NBER WORKING PAPER SERIES

\title{
INCONSISTENT POLICY EVALUATION: A CASE STUDY FOR A LARGE WORKFARE PROGRAM
}

\author{
Arthur Alik-Lagrange \\ Martin Ravallion \\ Working Paper 21041 \\ http://www.nber.org/papers/w21041
NATIONAL BUREAU OF ECONOMIC RESEARCH
1050 Massachusetts Avenue
Cambridge, MA 02138
March 2015

For their comments on an earlier version of this paper the authors thank Sylvain Chabé-Ferret, Pierre Dubois, Rinku Murgai, Dominique van de Walle, Jasmin Fliegner, Thomas Chaney, Jeanne Commault and seminar participants at the Toulouse School of Economics and at EDePo (IFS, London), and participants of 2014 EUDN workshop. Alik-Lagrange acknowledges support from Ecole Normale Supérieure-Cachan. The views expressed herein are those of the author and do not necessarily reflect the views of the National Bureau of Economic Research.

NBER working papers are circulated for discussion and comment purposes. They have not been peerreviewed or been subject to the review by the NBER Board of Directors that accompanies official NBER publications.

(C) 2015 by Arthur Alik-Lagrange and Martin Ravallion. All rights reserved. Short sections of text, not to exceed two paragraphs, may be quoted without explicit permission provided that full credit, including $(\odot$ notice, is given to the source. 
Inconsistent Policy Evaluation: A Case Study for a Large Workfare Program

Arthur Alik-Lagrange and Martin Ravallion

NBER Working Paper No. 21041

March 2015

JEL No. D61,H43,H53,J08,O15

\title{
ABSTRACT
}

Evaluations of workfare programs in poor rural economies have typically ignored two features that policy makers stress: involuntary unemployment and the expected welfare losses from work requirements. The paper generalizes past evaluation theory and methods to incorporate both features, and shows that doing so can switch the policy ranking in favor of welfare over workfare. A case study for India's massive National Rural Employment Guarantee Scheme indicates lower impacts on poverty than suggested by past methods, despite a more "poor-poor" incidence. A basic-income guarantee would dominate net workfare earnings in terms of the impact on poverty for a given budgetary outlay.

\author{
Arthur Alik-Lagrange \\ Toulouse School of Economics \\ arthur.alik@tse-fr.eu \\ Martin Ravallion \\ Center for Economic Research \\ Georgetown University \\ ICC 580 \\ Washington, DC 20057 \\ and NBER \\ mr1185@georgetown.edu
}




\section{Introduction}

The ways that social programs are analyzed and evaluated are sometimes in tension with the government's rationale for the intervention. For example, the widespread practice in both the literature and policy discussions has been to use consumption expenditure or income as the measure of household economic welfare in assessing the impacts of social programs. Yet the policy motivation typically assumes that people themselves do not care solely about their consumption or income. Indeed, both the motivation and mechanism design are often anchored to a broader concept of welfare. Thus there is an inconsistency between the policy and how it is evaluated. We dub this "inconsistent policy evaluation."

An example is found in the literature on microfinance schemes. Motivated by concerns about credit market failures, microfinance programs have aimed to support small-scale credit and savings transactions by poor people. The main outcome variable in past impact evaluations has been current consumption, as widely used in measuring poverty. ${ }^{2}$ Yet the presumption of creditmarket failure suggests that a first-order welfare impact comes from relaxing that constraint. This need not be evident in current consumption. Thus there is an inconsistency between how these schemes are often evaluated and the rationale of policy makers for the existence of the scheme. ${ }^{3}$

Another example - the focus of this paper — is found in the context of the longstanding policy issue of the choice between "workfare" and "welfare" as antipoverty policies. The key theoretical paper on this policy problem is Besley and Coate (BC) (1992). That paper made a valuable contribution in deriving conditions under which imposing a work requirement on welfare recipients yields a more cost-effective policy against poverty than transfers without such requirements. The key factor in favor of workfare is seen to be that it permits screening of the poor from the nonpoor, given imperfect information on heterogeneous abilities. This is the longstanding "self-targeting" argument for workfare. Yet the BC analysis has two features that are inconsistent with the arguments made by policy makers in favor of workfare schemes in poor rural economies, which have emphasized the existence of higher involuntary unemployment rates among the poorest and the fact that the type of work provided gives disutility. The BC

2 See, for example, Pitt and Khandker (1998). For a review of the arguments and evidence on these schemes see Ravallion (2015), which also discusses poverty measurement.

$3 \quad$ Also see Kanbur et al. (1994b) who discuss the sensitivity of targeting performance with respect to policy makers valuation of households effort when offered a poverty alleviation program implying labor supply adjustment. 
analysis assumes instead that there is full employment and that the policy maker attaches no welfare loss to the type of work done. ${ }^{4}$

This paper examines the implications of a consistent analysis/evaluation method for assessments of workfare. We consider the case of public work schemes in poor labor surplus economies and in exploring not only the impact on targeting performance and poverty, but also on the relative costs of these programs as opposed to basic income schemes. Modified BesleyCoate conditions are derived in a generalized framework addressing the two factors above that have so far been missing from the theory on the targeting performance and cost-effectiveness of public work scheme. ${ }^{5}$ The two omissions are logically related. Omitting the welfare loss implied by the work requirement is justified if poverty does not result from high unemployment rates among the poor. However, as we show, if involuntary unemployment exists and is negatively correlated with consumption levels then internalizing the welfare loss implied by the work requirement tightens the sufficient condition for workfare to be cost-effective. As in BC, it remains theoretically ambiguous whether workfare will dominate welfare even with asymmetric information. We thus turn to data.

The empirical context is the largest anti-poverty program in India (and undoubtedly the largest anywhere in terms of population coverage), namely the Mahatma Gandhi National Rural Employment Guarantee Scheme (NREGS for short). ${ }^{6}$ The existence of involuntary unemployment in the context of rural India's economy has been widely documented. ${ }^{7}$ NREGS is premised on the view that involuntary unemployment (or underemployment) is an important cause of poverty in this setting. ${ }^{8}$ The scheme promises 100 days of work per year per household to all rural households whose adults are willing to do unskilled manual labor at the statutory minimum wage rate notified for the program.

\footnotetext{
$4 \quad$ This is also true in the generalized framework developed in Besley and Coate (1995).

$5 \quad$ Basu (2013) considers the theoretical link between the existence of involuntary unemployed casual workers and the impact of MNREGA on agricultural output and laborers welfare.

$6 \quad$ Workfare has been widely used in crises and by countries at all stages of development. Famously, workfare programs were a key element of the New Deal introduced by US President Franklin D. Roosevelt in 1933 in response to the Great Depression. They were also a key element of the Famine Codes introduced in British India around 1880 and have continued to play an important role to this day in the sub-continent. Relief work programs have helped in responding to, and preventing, famines in Sub-Saharan Africa.

$7 \quad$ See Bardhan (1984).

$8 \quad$ The "MNREGA manual" recognizes explicitly the correlation between unemployment and poverty. The manual is available on the administrative website of the Ministry of Rural Development of the Government of India: see http://nrega.nic.in/netnrega/WriteReaddata/Circulars/MGNREGA manualjuly.pdf.
} 
Much has already been written on NREGS, typically focusing on its performance in reaching India's rural poor and reducing their poverty as measured by household consumption per person. ${ }^{9}$ However, consumption of commodities cannot be considered a satisfactory metric of welfare in this context, given that it ignores the fact that the work involved is physically demanding and even unpleasant and that many participating workers would probably not be working otherwise. One typically toils for long hours doing manual labor in the open sun at high temperatures, and with poor facilities and little or no likely job satisfaction. We contend that any reasonable ethical observer, whether a policy maker or an evaluator of the scheme, would conclude that casual manual labor in rural India is especially hard and unpleasant work by any standards and that such work entails a welfare loss at given consumption. Nor is it plausible that people in this setting would choose casual manual labor over regular non-manual work when available. Anyone who can get a regular non-manual job will take it in preference to doing casual manual labor. Furthermore, it is rare that someone does both. ${ }^{10}$

Yet the evaluation methods found in practice attach no welfare penalty to doing casual manual work. Two people with the same real consumption expenditure are deemed to be equally poor even if one of them derives all that consumption from hard grinding toil while the other enjoys leisure time or some relatively pleasant form of work.

The inconsistency here between the outcome measure used for evaluation and the policy-maker's rationale for the intervention is troubling. The fact that the work involved is unpleasant is one reason why workfare programs have long been used to fight poverty, in both rich and poor countries. The policy maker (implicitly or explicitly) agrees that the work is unpleasant and would almost certainly not consider doing it. The underlying mechanism design of workfare programs is based on incentives constraints in which work enters negatively in utility functions. How then can the policy maker justify ignoring the fact that the work is unpleasant when assessing the welfare gains from the program?

This is clearly problematic within a welfarist approach whereby "welfare" should only be assessed by whatever people maximize, even ignoring the well-known identification problems

\footnotetext{
$9 \quad$ Dutta et al. (2013) provides an assessment. Also see the discussions in Jha et al. (2009, 2012), Gaiha (1997), Bhalla (2011), Imbert and Papp (2011).

10 In India's National Sample Survey for 2010, only 7.6\% of all rural households reported both at least one casual manual work activity and another paid activity, and among those reporting at least one casual manual activity $77.4 \%$ did not report any other paid activity (both values are weighted shares using expansion factors). It appears that the vast majority of casual manual working households have little or no access to other paid activities, including regular non-manual work.
} 
involved in inferring utility from observed behavior. ${ }^{11}$ The evaluations in practice have invariably been non-welfarist. ${ }^{12}$ But that does not justify a situation in which the policy maker's rationale for the intervention is inconsistent with how it is being evaluated. If the policy maker judges that people are worse off doing this work, such that at a given income level only the poor will do so in expectation, then surely the evaluator cannot ignore the welfare loss from this work in assessing the program. ${ }^{13}$

Thus it is of interest to explore whether incorporating an ethically-motivated assessment of a welfare loss from the type of work done alters the theoretical justification of such a program and its evaluation. By welfare loss we do not refer here to households' utility loss, but rather to a consistent government's paternalistic assessment. Hence our approach differs from Besley and Coate (1995) who compare income maintenance and utility maintenance workfare programs.

There are two opposing effects of removing the ethical inconsistency in the evaluation. It is plain that, for any given participant, we will tend to over-estimate the benefits of the program by ignoring the welfare cost of doing the kind of work that NREGS provides. However, that does not imply that we will under-estimate the poverty impact of the scheme. To the extent that NREGS participants tend to come from households that already do casual manual labor, ignoring the welfare cost of doing that work will lead one to understate how well targeted such a program is to poor people, who will be even poorer (in terms of welfare) than their consumption suggests. And some participants who are not considered poor when the welfare cost of the type of work they do is ignored will now be seen to be poor.

Which of these two effects dominates will determine how the gains from the program are distributed across the population and (in combination with how the chosen poverty measure weights gains at different levels of living) whether or not the poverty impacts are underestimated by standard methods that ignore the welfare cost of work.

The paper examines the sensitivity of standard assessments of the cost-effectiveness of NREGS to ignoring the welfare loss from casual manual work. We consider the case of an evaluator caring about welfare losses implied by casual manual wage labor only. There are, of

\footnotetext{
$11 \quad$ See Pollak and Wales (1979) and Browning (1992).

12 For further discussion of this distinction in the context of antipoverty policy see Kanbur et al. (1994a) and Ravallion (2015).

13 Notice that the policy maker can think that the work is so unpleasant as to deter the non-poor but still believe that the extra work brings a welfare gain to the poor. This only requires the judgment that the income gain is enough to outweigh the direct welfare loss.
} 
course, other types of unpleasant work in this setting, but we want to define a welfare measure consistent with the motivation of the Act that created NREGS, which aims to provide casual manual work on public-works projects on demand. In practice, the main alternative to supplying casual manual labor (often for work on another farm) is working on one's own farm. We assume that the policy maker in this setting treats this as a very different form of work that gives little disutility to the farmer, at least relative to casual wage work. This is plausible in this context. Indeed, it can be expected that own-farm work gives personal satisfaction to a farmer that is more than enough to outweigh any disutility of the physical labor involved. We also assume that in the policy maker's view permanent work in this setting (such as working for the government or in a formal-sector enterprise) has very different welfare consequences. Here too there is likely to be significant job satisfaction. Indeed, studies of subjective welfare typically find that a regular job is a direct source of personal satisfaction, with a positive effect on perceived happiness or satisfaction with life. ${ }^{14}$ Although we do not know of any supportive evidence, it would seem a plausible assumption that casual manual wage labor in rural India provides little or no intrinsic job satisfaction; the overwhelming direct welfare effect is negative - to be balanced against the positive value of the gain in earnings. We comment on the likely direction of bias in our main results if the evaluation allows for other (non-casual non-manual) work entailing a welfare loss.

The paper proposes a simple data-consistent welfare objective for a workfare scheme that generalizes the standard consumption-based measure to allow for the unpleasant nature of casual manual labor. Following standard practice in the literature on anti-poverty programs (including workfare) we treat this as a non-welfarist assessment, meaning that we do not assume that the welfare metric is also what people maximize personally. ${ }^{15} \mathrm{We}$ do not assume anything about subjective utility. ${ }^{16}$ Using data on forgone income, we also allow for involuntary unemployment in the absence of workfare. This alters further the net impact and the cost effectiveness of workfare relative to a welfare program providing an un-targeted basic income.

This approach is in contrast to the tradition in labor economics, which assumes that people are free to choose their labor supply and that policy goals are solely utility-based. By this

$14 \quad$ For an overview of the evidence on this point see World Bank (2012).

15 Thus our exposition of the problem also departs from the optimal nonlinear income taxation literature were the government's goal is to maximize a utilitarian welfare function given by the sum of utilities, following Mirrlees (1971).

16 Our approach thus departs from Moffit's (2006) paternalistic preferences based on households utilities. 
approach one assumes that casual labor supply maximizes subjective utility and one finds preference parameters econometrically that are consistent with that assumption. There is a tradition in welfare measurement of deriving the parameters under that assumption, subject to certain (potentially strong) identifying assumptions. ${ }^{17}$ One can question the relevance of this approach to the setting at hand. Consistently with the presumption that there is widespread underemployment, our measure does not assume that workers are free to work as little or as much as they want. Nor do we assume that the welfare metric used by the policy maker/evaluator coincides with whatever people maximize. To our knowledge, it is rare for any impact evaluation to claim that the outcome variable used for assessing impact coincides with the utility function maximized by participants. Rather, it is the norm to impose an essentially non-welfarist objective. While we do not take issue with that approach here, we do question whether it is consistent to advocate a program as being effective because it imposes forgone income and welfare losses on participants (though not so much that they cease to participate) while ignoring those losses when we come to assess the program.

Importantly, our approach is operational with the same data currently used by most researchers in assessing the targeting and poverty impacts of NREGS. We then see how this affects assessments of the targeting performance and poverty impact of NREGS. On allowing for an imputed welfare cost of casual manual labor supply, we show that poverty and inequality measures for rural India are appreciably higher and that the program performs much better in reaching the poor. However, despite the better targeting, we find that NREGS (in the one state of India for which the required survey data are available) has somewhat lower poverty impacts when we discount the welfare gains to participants. ${ }^{18}$

The following section explains how the features of involuntary unemployment and consistency between the evaluation and the rationale for the intervention modify the theoretical conditions established by Besley and Coate (1992). Section 3 explains our empirical approach. Section 4 describes our data, while section 5 presents our evaluation method using those data. Our results are found in Section 6. Section 7 concludes.

\footnotetext{
$17 \quad$ For a useful overview of this approach see Blundell et al. (2007).

18 This is in line with the theoretical predictions from Besley and Coate (1992). They predict indeed a "selfdefeating" impact of the work-requirement itself if one is concerned about the welfare loss implied by the work offered.
} 


\section{Modified Besley-Coate conditions}

We generalize the model of Besley and Coate (BC) (1992) to derive the theoretical implications of an internalization of the welfare loss from work requirements, allowing for involuntary unemployment negatively correlated with consumption. We focus here on the screening argument, which is consistent with the primary goal of workfare programs in targeting transfers to poor people.

Following Moffit's (2006) generalization of BC, there is a continuous type of $N$ agents characterized by their wage rate $\alpha_{i} \in[\underline{\alpha}, \bar{\alpha}]$ with cumulative distribution function $F_{\alpha}$. A program is defined by a set of contracts $(B, P W)$ where $B$ and $P W$ are the benefit level and the publicwork requirement, which are constant over participants. ${ }^{19}$ Let $l^{1}\left(B, P W, \alpha_{i}\right)$ and $l^{0}\left(\alpha_{i}\right)$ denote private labor supply in the presence of the workfare scheme and in its absence respectively. The absence of involuntary unemployment on the private labor market calls for:

$$
l^{1}\left(B, P W, \alpha_{i}\right)_{\alpha_{i} \in[\underline{\alpha}, \bar{\alpha}]}=\left\{\begin{array}{cc}
l^{0}\left(\alpha_{i}\right)-P W & \text { if } P W<l^{0}\left(\alpha_{i}\right) \\
0 & \text { otherwise }
\end{array}\right.
$$

This is equivalent to $l^{1}+P W^{*}=l^{0}=l^{*}$ where $l^{*}$ is the optimal labor supply of an unrationed household on the private labor market. For now, we assume that (1) holds, but we relax this later. Earnings on the private sector are given by:

$$
y\left(P W, \alpha_{i}\right)_{\alpha_{i} \in[\underline{\alpha}, \bar{\alpha}]}=\left\{\begin{array}{cc}
\alpha_{i}\left(l^{0}\left(\alpha_{i}\right)-P W\right) & \text { if } P W<l^{0}\left(\alpha_{i}\right) \\
0 & \text { otherwise }
\end{array}\right.
$$

Notice that, as in BC, any income effect from the benefit $B$ is turned off. Utilities are linear in income but with a disutility of work given by the function $h($.$) :$

$$
v\left(B, P W, \alpha_{i}\right)_{\alpha_{i} \in[\underline{\alpha}, \bar{\alpha}]}=B+y\left(P W, \alpha_{i}\right)-h\left(l^{1}\left(B, P W, \alpha_{i}\right)+P W\right)
$$

A person takes up the program on a contract $(B, P W)$ if $v\left(B, P W, \alpha_{i}\right) \geq v\left(0,0, \alpha_{i}\right)$. For now the function $h($.$) is increasing, strictly convex and such that l^{0}$ is not a corner solution in the household's optimal choice of its labor supply, i.e. $h^{\prime}(0)=0$ and $h^{\prime}(\bar{l})>\bar{\alpha}$ where $\bar{l}$ is the

19 Here we depart from Besley and Coate (1995) where the government can define an optimal set of contracts for each ability type. Assuming a workfare with a single contract simplifies our derivations, but more importantly it is also consistent with what NREGS offers to rural households. 
maximum hours a household can supply given physical and market rationing constraints. ${ }^{20}$ This interior solution assumption is crucial; it implies the absence of involuntary unemployment in (1).

Now consider the screening argument in a situation in which the evaluator cares about the welfare loss implied by the work requirement. In our set up, the government aims to bring everyone above a poverty line, $z$. Consistently with the literature, we assume that in the absence of the scheme low-wage workers are poor and high-wage ones are rich and that they are separated by a given poverty line $z$ where households are characterized by wage rate $\alpha_{z}$. However, we modify this assumption allowing the welfare loss to be internalized by the government:

$$
y\left(0, \alpha_{i}\right)-f\left(l^{0}\left(\alpha_{i}\right)\right)<z<y\left(0, \alpha_{j}\right)-f\left(l^{0}\left(\alpha_{j}\right)\right), \forall \alpha_{i}<\alpha_{z}<\alpha_{j}
$$

Here $f($.$) is the paternalistic welfare loss identified by the government. Notice that for f=h$ this problem is close to the utility maintenance programs described in Besley and Coate (1995). We do not assume that the government internalizes the welfare loss caused by the work requirement in a utilitarian way. In this perspective our approach differs also from Moffit's (2006) paternalistic government preferences in that we do not base the definition of $f($.$) on the$ underlying household preferences. We only assume that in the government's view working more at a given consumption level reduces households' welfare, i.e., $f^{\prime}(l)>0$. The objective of the government is to get low-wage workers above the poverty line at minimum cost:

$$
B+y\left(P W, \alpha_{i}\right)-f\left(P W+l^{1}\left(B, P W, \alpha_{i}\right)\right) \geq z \forall \alpha_{i}<\alpha_{z}
$$

Full information: First consider the case when the government can observe wage rates and private earnings. The government faces voluntary participation and poverty alleviation constraints:

$$
\begin{aligned}
& v\left(B, P W, \alpha_{i}\right) \geq v\left(0,0, \alpha_{i}\right) \quad \forall \alpha_{i} \\
& B+y\left(P W, \alpha_{i}\right)-f\left(P W+l^{1}\left(B, P W, \alpha_{i}\right)\right) \geq z \forall \alpha_{i}
\end{aligned}
$$


respectively. In this case, the cost minimizing program is obviously a welfare program. Any public work requirement $P W>0$ implies forgone earnings that the government would have to compensate for-against no gains from targeting. The government then offers:

$$
\begin{aligned}
& \left(B_{j}, P W_{j}\right)=\{0,0\} \quad \forall \alpha_{j}>\alpha_{z} \\
& \left(B_{i}, P W_{i}\right)=\left\{z-y\left(0, \alpha_{i}\right)+f\left(l^{\text {pre }}\left(\alpha_{i}\right)\right), 0\right\} \forall \alpha_{i}<\alpha_{z}
\end{aligned}
$$

The costs of the program is $N \int_{\underline{\alpha}}^{\alpha_{z}}\left[z-y\left(0, \alpha_{i}\right)+f\left(l^{\text {pre }}\left(\alpha_{i}\right)\right)\right] F_{\alpha}\left(\alpha_{i}\right) d \alpha_{i}$. This is higher than the costs derived in BC if $f\left(l^{0}\left(\alpha_{L}\right)\right) \neq 0$, otherwise it is exactly the same up to the generalization to allow a continuous distribution of wage rates.

Asymmetric information: Suppose now that the government cannot observe wage rates and private earnings. In the absence of a public work requirement, high wage workers will masquerade and take up the program to receive benefits. Then the government can use a publicwork requirement for screening. This targeting advantage of workfare comes at a cost, namely that the net gain to poor people is lowered by the cost of complying with the work requirement. Intuitively, workfare is more likely to be the better option when the poverty rate is lower and/or the forgone income of workfare participants is lower. Following BC, we show that a sufficient condition for workfare to be more cost-effective than welfare is that $\left(\alpha_{z}-\underline{\alpha}\right)>F_{\alpha}\left(\alpha_{z}\right) \alpha_{z}$ or $\underline{\alpha}<\left(1-F_{\alpha}\left(\alpha_{z}\right)\right) \alpha_{z}{ }^{21}$

The internalization of the welfare loss does not impact this condition. Indeed, whether the government cares about the participants' welfare loss does not matter if they can supply as much work as they want to on the labor market in the absence of the scheme. Essentially, low wage workers pay in order to be screened as being poor in the form a work requirement, but under the full employment assumption they would anyway spend this time working. The scheme implies no net welfare loss and the only trade-off faced by the government remains that between limiting cash transfers to high wage workers and having to compensate low wage workers for forgone incomes implied by the time spent on public work.

We can summarize the implications as follows (with a formal proof and closed form solutions found in the Appendix):

$21 \quad$ See Besley and Coate (1995) for a technical discussion on whether a solution to the government's costsminimizing program does exist depending on assumptions on the distribution of $\alpha_{i}^{\prime} s$ and on the shape of $h()$. 


\section{Proposition 1: Under the labor-market clearing condition, whether or not the evaluator cares about the welfare loss implied by the work requirement does not alter the BC condition for the workfare program to be cost-minimizing, namely that $\left(\alpha_{z}-\underline{\alpha}\right)>$ $F_{\alpha}\left(\alpha_{z}\right) \alpha_{z}$. However, internalizing part of the welfare loss increases the length of the work requirement and the transfers needed for poverty alleviation.}

The increase in the length of the work requirement may appear counterintuitive here, but the intuition is restored if one observes that the benefits increase with the length of the work requirement (see Appendix).

Introducing involuntary underemployment: We now relax the assumption that poor households can supply as much work as they want on the private labor market. Then the time spent working on public works overlaps only partly with the time the participant would spend working in the absence of the scheme. We thus modify the labor supply schedule as follows:

$$
l^{1}\left(B, P W, \alpha_{i}\right)_{\alpha_{i} \in[\underline{\alpha}, \bar{\alpha}]}=\left\{\begin{array}{cc}
l^{0}\left(\alpha_{i}\right)-s_{i} P W & \text { if } s_{i} P W<l^{0}\left(\alpha_{i}\right) \\
0 & \text { otherwise }
\end{array}\right.
$$

This is equivalent to $l^{*} \geq l^{1}+P W \geq l^{0}$, meaning we do not assume anymore that $h^{\prime}(\bar{l})>\bar{\alpha}$. Labor supply in the absence of the scheme may now be a corner solution $\left(l^{0}=\bar{l}\right)$. Let $s_{i}$ denote the share of the work requirement that the individual would spend working in the absence of the scheme: $s_{i}=1$ means that workers supply as much work as they want in the absence of the scheme, and $s<1$ means they are rationed on the labor market. While $s_{j}=1$ can be seen as realistic for rich households, we must relax this for low wage workers. We assume instead that:

$$
s_{k} \leq s_{i}<1, \quad \forall \alpha_{k} \leq \alpha_{i}<\alpha_{z}^{22}
$$

Notice that the unemployment is involuntary: at the offered wage rate on the private market, poor households would be typically willing to supply more work. Poverty is now correlated with both low wages and involuntary unemployment. ${ }^{23}$ Earnings from the private sector are now:

\footnotetext{
22 In theory, our model can always fit the data if one define the poverty line as the $\alpha$ above which no one is involuntary unemployed, meaning the only assumption we really need is $s$ increases with $\alpha$ and reaches its upper bound for some interior values: $\exists \alpha<\bar{\alpha} \mid\left(\forall \alpha \alpha_{i}>\alpha, s_{i}=1\right)$.

23 We do not explain where involuntary underemployment comes from, and how it relates endogenously with other variables of our model; see Basu(2013) for an example of an explicit model. Nor do we explore any causal relationship between wage rates, unemployment and poverty. The only statement we need for our results to be valid
} 


$$
y\left(P W, \alpha_{i}\right)_{\alpha_{i} \in[\underline{\alpha}, \bar{\alpha}]}=\left\{\begin{array}{cc}
\alpha_{i}\left(l^{0}\left(\alpha_{i}\right)-s_{i} P W\right) & \text { if } s_{i} P W<l^{0}\left(\alpha_{i}\right) \\
0 & \text { otherwise }
\end{array}\right.
$$

The poverty alleviation constraint becomes, $\forall \alpha_{i}$ :

$$
\begin{aligned}
& B+y\left(P W, \alpha_{i}\right)-f\left(P W+l^{1}\left(B, P W, \alpha_{i}\right)\right) \geq z \\
& B+y\left(P W, \alpha_{i}\right)-f\left(\left(1-s_{i}\right) P W+l^{0}\left(\alpha_{i}\right)\right) \geq z
\end{aligned}
$$

In the full information case, the result is not changed. The government offers a welfare program $(P W=0)$ with no transfer to high wage households and it gives to each low-wage worker:

$$
z-y\left(0, \alpha_{i}\right)+f\left(l^{\text {pre }}\left(\alpha_{i}\right)\right), \forall \alpha_{i}<\alpha_{z}
$$

In this case the costs are the same as before and unemployment has no impact on the costs of the welfare program.

In the asymmetric information case incentives are unchanged $\left(s_{j}=1, \forall s_{j} \geq s_{z}\right)$. If the government does not internalize the welfare loss $(f()=0$.$) then we can summarize the modified$ $\mathrm{BC}$ conditions in the following proposition, which is proved in the Appendix:

\section{Proposition 2: If the poor face higher involuntary unemployment in the absence of the scheme than the non-poor and the evaluator does not internalize the welfare loss implied by the program then the modified $\mathrm{BC}$ condition for the workfare program to be more cost- effective than welfare is that $\left(\alpha_{z}-\underline{s \alpha}\right)>F_{\alpha}\left(\alpha_{z}\right) \alpha_{z}$.}

This is intuitive: if the poor do not find other work during the time spent satisfying the work requirement then the forgone earnings implied by workfare are lower than in the market clearing case, which reduces the transfers needed for poverty alleviation. Notice that the standard BC condition $\left(\alpha_{z}-\underline{\alpha}\right)>F_{\alpha}\left(\alpha_{z}\right) \alpha_{z}$ remains sufficient. However, the modified condition in Proposition 2 is less restrictive in that:

$$
\left(\alpha_{z}-\underline{\alpha}\right)>F_{\alpha}\left(\alpha_{z}\right) \alpha_{z} \Rightarrow\left(\alpha_{z}-\underline{s \alpha}\right)>F_{\alpha}\left(\alpha_{z}\right) \alpha_{z}
$$

is the statistical correlation between those variables, which is widely documented in the literature and observed in the data we use later. 
The combination of unemployment and internal consistency on the part of the government's evaluation $(f() \neq 0$.$) further alters the BC conditions for workfare to be more cost$ effective, as in the following proposition (also proved in the Appendix):

Proposition 3: If the poor face unemployment in the absence of the scheme and the government internalizes the welfare loss implied by workfare then the modified BC sufficient condition for the workfare program to be more cost effective than welfare is that $\left(\alpha_{z}-\underline{s \alpha}\right) K>F_{\alpha}\left(\alpha_{z}\right) \alpha_{z}$ where

$$
K \equiv 1+\frac{f\left(l^{0}(\underline{\alpha})\right)-f\left((1-\underline{s}) P W^{*}+l^{0}(\underline{\alpha})\right)}{z-\underline{\alpha} l^{0}(\underline{\alpha})+f\left((1-\underline{s}) P W^{*}+l^{0}(\underline{\alpha})\right)}<1
$$

Evidently this case is more restrictive than the previous one; indeed $\left(\alpha_{z}-\underline{s \alpha}\right) K>$ $F_{\alpha}\left(\alpha_{z}\right) \alpha_{z}, K<1 \Rightarrow\left(\alpha_{z}-\underline{s \alpha}\right)>F_{\alpha}\left(\alpha_{z}\right) \alpha_{z}$.

We see that in the presence of unemployment positively correlated with low ability and poverty, the internalization of the welfare loss tightens the sufficient condition for workfare to be more cost effective than welfare. From this theoretical discussion we conclude that workfare evaluation in practice should internalize the welfare loss implied by the type of work observed when poor participants would be more often involuntary unemployed than richer ones in the absence of the scheme. Under these assumptions we see that such an internalization can switch the cost-effectiveness ranking in favor of a welfare.

We turn next to the data, exploring how the internalization of the welfare loss from the work requirement of NREGS alters the impact evaluation.

\section{Welfare measurement}

As discussed in the Introduction we impute a welfare loss from casual manual labor. Our welfare measure is a function of both consumption and casual manual work, the former variable entering positively and the later negatively.

We assume that regular non-manual work dominates in both its remuneration and enjoyment, such that the worker will do as much of that work as available (given her skills, experience and constraints on the casual manual labor market) before contemplating any casual 
manual labor. We acknowledge that this is a strong assumption in the abstract, but we believe it is plausible and appropriate in this context. As a stylized fact, casual manual workers in rural India do not have the option of accessing non-manual regular jobs. Support for this can be found in the survey findings for the state of Bihar in Dutta et al. (2014). Their survey asked participants in NREGS what they think they would have been doing if not for the work they obtained on the scheme. Amongst male respondents, $45 \%$ said they expect they would have been doing casual work (farm or non-farm), and about the same proportion said they would be unemployed, searching for work. The rest said they would be working on their own land or in their home. Women expected to get less casual work and were more likely to be working at home. Strikingly, none of the (male or female) survey respondents identified non-manual regular employment as an option. Of course, NREGS workers are a selected sample. However, Dutta et al. find almost no observable differences between NREGS workers and other casual laborers. The reality on the ground appears to satisfy an even stronger assumption than we require here, namely that the labor market is segmented, with all those having access to a regular non-manual job doing that job, and doing no casual manual labor, while the rest do as much casual work as they desire (or can find, if there is unemployment).

To make our approach operational with the data available, we assume that welfare is assessed by adjusted consumption as given by:

$$
C_{i}^{A}=C_{i}-\omega L_{i}
$$

where $C_{i}$ is ordinary consumption, $\omega \geq 0$ is a parameter reflecting the welfare penalty attached to doing casual manual labor in the amount $L_{i}$. Adjusted consumption entails a downward adjustment relative to $C_{i}$ for households supplying casual labor $\left(L_{i}>0\right)$ but no adjustment otherwise $\left(L_{i}=0\right)$. The distributions of $C_{i}$ and $C_{i}^{A}$ are not intrinsically level comparable, so we will mainly use percentiles rather than levels.

Equation (12) is not, of course, the only way one might adjust the welfare measure for the welfare loss deemed to be associated with doing casual manual work. More complex functional forms could be proposed, allowing (for example) for non-separability between casual manual labor supply and consumption. However, we want a functional form that delivers an empirically tractable welfare metric allowing for the welfare cost from casual work, which can be implemented with the same data used by the standard method in which welfare is solely measured by consumption. With the functional form in (12) we obtain a very intuitive 
expression for how the standard measure of consumption could be adjusted to reflect the welfare cost of casual manual labor in the view of a policy maker, giving the adjusted consumption.

The implications of this adjustment for measures of poverty and inequality are ambiguous in theory, and will depend on the data, notably how $L_{i}$ varies with $C_{i}$. It is instructive to consider one special case, namely when $L_{i}$ is decreasing in $C_{i}$, as suggested by Figure 1 . Measured consumption will be adjusted downwards for the poorest, and upward for the richest. There will not be first-order dominance, but all standard poverty measures will increase for poverty lines up to the mean. Standard inequality measures will naturally increase; more precisely, there will be Lorenz curve dominance, with unambiguously higher inequality in the adjusted distribution. Just how much the poverty and inequality measures are affected is (of course) an empirical issue and depends on the particular functional form used by the evaluator.

The implications for a workfare scheme's impact on poverty are also ambiguous in theory. As discussed in the Introduction, we expect our adjustment for the disutility of casual manual work to reveal better targeting to poor people who are more likely to do this type of work, as provided by NREGS. Against this, the effect on the welfare gains to participants of allowing for the welfare loss from the work provided will go in the opposite direction.

How should one set $\omega$ ? This can be recognized as a normative judgment for making inter-personal comparisons of welfare. For the purpose of making consistent inter-personal comparisons we need to impose common preferences, so we need to use one reference value of the parameter. However, we do not assume that workers maximize (12). They may well have other preferences, and even if they did not it would be unrealistic to assume that casual workers are free to choose their labor supply in this setting; indeed, this would be inconsistent with the rationale for NREGS, which rests on the existence of involuntary unemployment/underemployment of casual labor, implying that workers are not free to supply as much labor as they would like. Some workers are unable to get as much work as they would like at the going wage rate.

To bound the value of $\omega$ we make the following assumption: The evaluator (or policy maker) judges that casual labor is welfare diminishing at given consumption but, nonetheless, that the typical casual worker is better off with extra work if she chooses to do it. This is defensible in this context, for it would be hard to imagine why a policy such as NREGS would exist at all if the work provided was not deemed to increase welfare, even if it not by as much as 
the increment to consumption alone would indicate (notice that households are free to participate or not). This requires that:

$$
\frac{\partial C_{i}^{A}}{\partial L_{i}}=\frac{\partial C_{i}}{\partial L_{i}}-\omega>0
$$

We assume that the consumption is given by:

$$
C_{i}=W_{i} L_{i}+C_{i}^{0}
$$

Where $C_{i}^{0}$ is independent of the amount of casual work done at the wage rate $W_{i}$. Thus equation (13) establishes that $\omega$ is bounded above by $W_{i}$.

This simply tells us that the government in this setting internalizes the welfare loss implied by the type of work required at a rate not exceeding the typical wage rate paid for casual manual work. We thus consider a range of values of $\omega$ in a neighborhood of the median of this wage rate.

\section{Setting and data}

Rural India is characterized by higher unemployment rates among the poorest and one of the explicit goals of NREGS is to provide work to those households rationed on the private labor market. Figure 1 shows the link between low wage rates, unemployment and position along the per capita consumption distribution in the NSS for rural areas. We see that unemployment is more prevalent for the bottom part of the consumption distribution, which shows lower wage rates. Among working households, the lower the median wage rate in the household the more prone it is be unemployed. These observations place us in the third case described above and proposition 3 applies in this context.

The literature on poverty in India has also emphasized the link with casual manual labor and the real wage rate for that work. ${ }^{24}$ This is seen to be mainly driven by the strong correlation between rural landlessness and poverty, such that the rural poor are more likely to depend on agricultural labor. This is illustrated by Figure 2, which gives the non-parametric regression function of the participation rate in casual manual labor in rural India (top) and rural Bihar (bottom) against the percentile of household consumption per person; the regression allows for

24 See, for example, Bardhan (1984), van de Walle (1985), Datt and Ravallion (1998), Deaton and Drèze (2002). 
state effects. ${ }^{25}$ We see a marked decline in the average participation rate from almost $50 \%$ for the poorest percentile to zero for the richest. This presumably reflects both the disutility of casual manual work and the availability of better options for richer households in the form of regular, non-manual, work, which is more pleasant and better-paid.

We use two household data sets. The first is the 66th round (July 2009-June 2010) of the Employment Schedule ("Schedule 10") of the Government of India's National Sample Survey (NSS). These data include household characteristics (including demographics, NREGS participation, social groups) and information on household members' education, principal and subsidiary activity and time disposition during the week ended (block 5.3). The questionnaire also includes a block on monthly household expenditures during the last 30 days (block 9). We observe the weekly supply of casual manual work and also the daily wage rate for this type of work during the week ended (in block 5.3). The daily wage rate of a household is defined as its total earnings from casual manual work divided by total number of days spent on such work across all household members during week ended (status code 41, 42 and 51). Table 1 gives summary statistics on $L_{i}, C_{i}$ and $W_{i}$.

To facilitate estimation of the net gains to participants and to test the robustness of our results using the NSS, we will also use another household dataset collected in rural areas of the state of Bihar with support from the World Bank. In 2010, Bihar had the highest poverty rate of any major state of India (Dutta et al., 2012). Two rounds of survey data were collected for 3,000 randomly chosen households from 150 random villages spread across Bihar. The first round was between May and July of 2009 and the second during the same months one year later. A twostage sampling design was followed, using the 2001 Census list of villages as the sampling frame. Data were collected through several survey instruments, including household surveys and individual surveys, the latter for one adult male and one adult female in each household. Dutta et al. (2014, Chapter 3) contains a fuller description of the survey design. In this paper we only report results for the first round of the Bihar survey, which is designed to be representative of rural Bihar. However, we did all our analysis for the second round as well and all qualitative findings reported for Round 1 were found to be robust.

25 The estimation used the partial linear regression routine, PLREG, in Stata (Lokshin, 2006). The state effects entered as additive dummy variables. 
The World Bank's Bihar Survey contains similar variables to the NSS data (including on consumption), but provides more detail on participation and other variables related to NREGS. ${ }^{26}$ Importantly, the Bihar survey includes self-reported estimates of forgone work and earnings for NREGS participants. The Bihar Survey contains a block on time spent on casual work during the week ended, with total number of days and incomes for each activity (block 23). Thus we are able to estimate income gains (net of forgone earnings) from NREGS in Bihar, and impacts on poverty directly from the data. As a stylized fact, virtually the only options NREGS participants have for earning income in this setting are from casual manual work for a local landowner or on some non-agricultural activity. Most participants are landless and have lived in the villages for generations. They can be presumed to have a clear idea of their labor-earning options throughout the agricultural year, and hence can be expected to have reasonably reliable estimates of their forgone earnings.

\section{Performance evaluation}

Do the poorest participate more and do they get higher gains? By comparing the distributions of unadjusted consumption $C_{i}$ with adjusted consumption $C_{i}^{A}$ we are able to quantify the impact of allowing for the welfare loss from work on assessments of the program's performance. There are two aspects of performance. The first is targeting performance. Here we analyze the relationship between the participation rates in NREGS and the position along the distribution of consumption per capita. Using the two different welfare measurements, $C_{i}$ and $C_{i}^{A}$, we estimate $p$ and $p^{A}$ defined as non-parametric regression functions between the participation rate $(P R)$ and the position along the distribution of these two measurements: ${ }^{27}$

$$
\operatorname{PR}\left(x_{i}\right)=p\left(F_{C}\left(x_{i}\right)\right)+\varepsilon_{i}
$$

and similarly for the adjusted consumption, for which the non-parametric function is denoted

26 One difference is that we do not have the split manual/non-manual work in the Bihar survey: we only know if the activity was or was not casual work. This implies higher participation rate in this type of work in the Bihar Survey (21.1\% in the NSS data on rural Bihar versus $39.8 \%$ in the Bihar Survey).

$27 \quad$ We used the method of cubic splines smoothing, enabling us to produce point wise $95 \%$ confidence intervals. For Figure 1 and Figure 7 we use instead a running-line least-squares smoothing using Cleveland's (1979) tricube weighting function, as programmed in Stata (as the "lowess" command). When applying these methods, we use an arbitrary smoothing parameter to obtain smooth enough estimate of the regression functions. We could have used a cross-validated bandwidth instead, but for the essentially graphical purposes of this estimation we followed Deaton (1989) in selecting a bandwidth such that gives enough smoothness without losing detail, thus also avoiding the computational burden implied by cross-validated bandwidth selection. 
$p^{A}$. Thus $P R(x)$ is the participation rate observed for a given level of consumption $x$ and $F_{C}($. is the cumulative distribution function (CDF) of consumption. $p$ and $p^{A}$ are smooth nonparametric functions to be determined empirically. ${ }^{28}$ If the program is indeed better targeted in terms of adjusted consumption $C^{A}$ then we should observe that the function $p^{A}$ has a lower gradient than $p$.

Second, we study the impact of our adjustment on the gains from the scheme. For this purpose we use household-specific estimates of forgone income for men and women from the Bihar Survey. These are answers to the questions: "If you were doing some other work instead of this during these days, how many days do you think you would have worked?" and "If you were doing some other work instead of this during these days, what wage would you might have earned per day?"29 (The NSS does not contain these questions, which were developed for the Bihar survey.) The post-NREGS distribution of consumption is that observed in the data. Without the adjustment for the welfare loss from manual labor the pre-NREGS distribution is derived from the post-NREGS distribution simply by subtracting the net gains from the scheme, as given by gross wages less the imputed forgone income as reported by the household. An alternative way would be to estimate a wage regression and use estimates to predict earnings in the absence of the scheme, but it would be recall that our aim here is to illustrate the impact on poverty elevation and costs effectiveness for a given arbitrarily chosen function $f$ rather than producing an operational impact evaluation.

The gain from the scheme is then defined as (in obvious notation) $G_{i}=C_{i}^{1}-C_{i}^{0}$. The calculation is more complicated for the adjusted consumption, for which the gain is $G_{i}^{A}=C_{i}^{A 1}-$ $C_{i}^{A 0}$ where:

$$
C_{i}^{A j}=C_{i}^{j}-\omega L_{i}^{j} \quad(j=1,0)
$$

We analyze then the relationship between the net gains and the position along the consumption distribution, both original and adjusted, following a similar non-parametric approach described above for participation.

$28 \quad$ Alternatively we can focus directly on the relationship between $P R$ and $x$ (rather than $F(x)$ ). However, using $F(x)$ for the horizontal axis assures an even spread of data points, giving an incidence graph that is less prone to outliers at the extremes.

$29 \quad$ For further discussion see Dutta et al. (2014). 
In aggregating these gains we use the popular headcount index $(\mathrm{H})$, given by the proportion of the population living in households with mean consumption below the poverty line. However, it is of interest to also look at two "higher-order" measures, for which we use the poverty gap (PG) index, to also reflect the depth of poverty, and the squared poverty gap (SPG) index, which penalizes inequality amongst the poor, and can thus be interpreted as reflecting the severity of poverty. All three measures are members of the Foster-Greer-Thorbecke (1984) class of additive measures.

Costs effectiveness: In assessing NREGS we consider the impact on poverty of a counterfactual welfare program in which the government's outlay on NREGS wages is used instead to provide a uniform lump-sum transfer to all, whether poor or not, i.e., a basic income guarantee scheme. We do this with and without internalizing the welfare losses from participating, which makes sense considering the high observed unemployment rates among the poor.

In practice, we calculate $\mathrm{H}$ for pre- and post-adjusted and unadjusted consumption per capita, which gives the impact of NREGS's on poverty as directly observed from the data. We then evaluate what would be the impacts of a welfare program with same costs, i.e. we give to all households an equal share of the observed government's outlay on the top of their consumption in the absence of the scheme. We then re-calculate the poverty measures with this counterfactual consumption $\widetilde{C_{l}}$.

Note that this comparison does not take account of any other benefits to the poor from NREGS. There are undoubtedly some benefits from the asset creation, although this is not emphasized as a goal of the scheme. It has also been argued by advocates of the scheme's demand-driven nature helps empower workers, which may well have benefits in other respects. There may also be other (indirect) benefits of a basic-income guarantee.

\section{Results}

We set a benchmark value of $\omega$ at the median wage rates observed in the Bihar survey: 70 rupees per day per capita. Figure 3 shows a kernel estimation of the distribution of $W_{i}$. In both datasets the distribution of $W_{i}$ is skewed to the right. There are outliers, which support our use of the median instead of the mean. However, we will consider a range of values for $\omega$ up to $W_{i}$, 
consistent with our assumption that the policy maker judges that the typical worker is better off with extra work if she chooses to do it.

We first consider the effects of the adjustment for the welfare loss from casual manual work on measures of poverty and inequality based on the post-NREGS distributions. ${ }^{30}$ Table 2 summarizes the joint distribution of $C_{i}$ and $C_{i}^{A}$. Given that there is a higher incidence of casual manual work in the poorer segments of the population, it is to be expected that the lower part of the distribution is impacted more by the consumption adjustment. Our adjustment for the welfare loss from work has an impact on measured poverty and inequality. Figures 4 and 5 show respectively the cumulative distribution functions and the corresponding Lorenz curves. ${ }^{31}$ As is evident in Figure 4, we do not have first-order dominance, so the ranking in terms of any standard measure of poverty will depend on the precise measure used and the poverty line (Atkinson, 1987). Poverty measures are higher under our adjustment for the welfare loss from work up to about the 40th percentile.

Table 4 gives the impacts of our adjustment on the PG and SPG indices for both datasets. Recall that the distributions are not level comparable, so here we are measuring the effects on poverty at a given mean, interpretable as the "distributional component" of the poverty measure (Datt and Ravallion, 1992). In the all-India NSS sample, and using the median post-NREGS as the poverty line, the PG index rises from $13.7 \%$ to $34.8 \%$, while the SPG index rises from $5.1 \%$ to $43.4 \%$. Inequality is unambiguously higher after our adjustment for the welfare loss from work (Figure 5). In order to quantify this increase in inequality, we report in Table 3 the corresponding Gini coefficients calculated before and after the adjustment for the welfare loss from work. For the first implementation (using the whole NSS), the Gini coefficient rises from $31 \%$ to $56 \%$, which is a substantial increase. Comparing the Bihar sample of the NSS with the World Bank's Bihar survey sample as a whole, the rise in Gini coefficient is clearly higher for NSS Bihar (+0.25 for NSS Bihar versus +0.12 for World Bank survey sample as a whole).

Turning next to assessments of targeting performance, we estimate $p^{A}$ and $p$ for the NSS data (rural households only) using again $\omega=70$. The result of this estimation is showed in Figure 6 (top). For both $p^{A}$ and $p$ the participation rate decreases as consumption rises. Using

\footnotetext{
$30 \quad$ Recall that we can only measure the net gains due to the program using the specially-designed World Bank Bihar survey. Thus we can only derive pre-NREGS consumptions for that dataset.

$31 \quad$ Here and elsewhere we use household weights (expansion factors) to assure that the sample-based calculations are representative of the population in the base year.
} 
the original consumption (without our adjustment) we see that participation rates are lower than average for roughly the richest $50 \%$, but we see no clear sign of better targeting within the poorer half of the distribution ( $p(x)$ is quite flat for $x \in[1,50]$ ). However, after adjusting for the welfare loss from work, we see much better targeting performance among the poor, particularly for $F_{C_{i}^{A}}(x) \in[10,40]$. We also provide $95 \%$ confidence interval bounds, showing significance of these features. Except when the two curves cross (around the median, i.e. $x=50$ ) and for the richest quintile, $95 \%$ pointwise confidence bands do not overlap.

We test for robustness with respect to the choice of $\omega$. For this purpose, we repeat the analysis using several values for $\omega$ (Figure 7). We test with $\omega=35$ and 105, respectively half of the median and 1.5 the median. We observe an improvement of measured targeting performance when increasing the rate at which welfare from casual manual loss is internalize.

Redoing the same estimation on the Bihar Survey, we find that $p(x)$ is flatter than $p^{A}(x)$ for the poorer half of the distribution (Figure 6). In the Bihar Survey, the adjusted version shows good targeting performance on the entire wealth distribution with $\frac{\partial p^{A}(x)}{\partial x}<0, \forall x \in[1,100]$. $^{32}$ We see better targeting performance when using $C_{i}^{A}$ instead of $C_{i}$, with less impact of the adjustment among the richest $30 \%$. This is implied by our particular choice of the welfare function, but as already mentioned any other function in which $C_{i}$ would enter positively and $L_{i}$ negatively would lead to the same results, up to their magnitude, would $\mathbb{C}\left[C_{i}, L_{i}\right]<0$ hold.

It will be recalled that the above calculations only adjust for the welfare loss from casual manual wage labor. As noted in the introduction, this is a type of work in this setting that is likely to be regarded by the policy maker as yielding disutility_far more so than selfemployment on one's own farm or regular salaried work. But that is an assumption on our part. If in fact these other forms of work are also seen as yielding disutility then we expect that the corrected targeting performance will not be as pro-poor as we report above, using only our adjustment for the welfare loss from casual manual wage work. Given that we will now show that (for Bihar at least) the improvement in measured targeting performance is not great enough to outweigh the reduced benefits of participation in NREGS when we allow for the welfare loss from the work provided, our main qualitative conclusion concerning the poverty impacts will remain valid. 
Using the Bihar survey we can also study the distribution of the net gains from the scheme along the distribution of $C_{i}^{A}$ and $C_{i}$. Figure 8 shows how the mean net gains against preNREGS consumption, with and without our adjustments, for various values of $\omega$. We see from Figure 8 that the net gains from the scheme are highest for the poorest using un-adjusted consumption, but the impacts are attenuated when we adjust for the welfare loss from the work provided by the scheme. This is mechanically implied by the fact that poor participants are more prone to be unemployed would they not be participating.

Table 5 gives the impacts of NREGS earnings on poverty for both the population as a whole and for the sub-sample of NREGS participants for $\omega=35,70,105$. We give results using a poverty line set at the median of the post-NREGS distribution of (un-adjusted) consumption, this for each $\omega$. Notice that we now compare HDI for $C_{i}^{A 1}$ and $C_{i}^{A 0}$ which are level comparable for a given $\omega$. We see that the poverty measures (both post-NREGS and pre-NREGS) are generally higher with our adjustment for the welfare loss from casual manual labor. The impact estimates for the HDI and PGI (post-NREGS less pre-NREGS) are found to be lower for both poverty measures after adjusting for the welfare loss from labor. ${ }^{33}$ For the SPGI the internalization seems to improve the impact measured. As implied by Figure 8, poverty impacts for the population as a whole are little affected by our adjustment for the welfare loss from work.

Table 6 gives the poverty impacts of the welfare scheme providing an untargeted basic income to all, in amount determined by the outlays on wages under NREGS as observed in our data. ${ }^{34}$ Comparing Tables 5 and 6 we see that for $\omega=0$ the poverty impacts are very similar. However, at higher values of $\omega$ we see that the welfare scheme dominates the workfare scheme, as predicted by our theoretical model.

\section{Conclusions}

Workfare schemes typically, and deliberately, offer unpleasant work. In the case of India's National Rural Employment Guarantee Scheme the work provided is monotonous manual labor, toiling for long hours in the open sun. Nobody is likely to enjoy this work, and that is undoubtedly part of the reason that relatively rich people appear to only rarely turn up for

\footnotetext{
33 Notice also that the impact on the income-gap ratio-namely the mean distance of the poor below the line, as a percentage of the line (i.e., the ratio of the PG index to the headcount index) - is also lower with our adjustment. 34 An alternative option is to derive the outlays from administrative data, as is done in XXX (ref to the WBER "Is workfare cost-effective in a poor labour-surplus economy?").
} 
work on the scheme, on top of their (probably) higher opportunity costs on the private labor market. Yet, while this "self-targeting" mechanism is a key aspect of the rationale for such schemes, the fact that the type of work is unpleasant for participants has never (to our knowledge) been used in assessing the impact of NREGS or other workfare schemes, nor has it been included in the theoretical models that underpin the evaluations of such programs. This is an ethically troubling inconsistency. And we have demonstrated that it has bearing on the results of the evaluation.

Depending on to what type of activities participating households do in the absence of the scheme, and whether or not the evaluator cares about the disutility implied by the scheme, workfare programs may appear more or less cost effective as compared to welfare programs providing un-targeted transfers (a basic-income scheme). On generalizing the long-standing model in Besley and Coate (1992) we have derived the tighter constraint for workfare to dominate welfare implied by higher unemployment rates for poorer households and a consistent evaluation, such that the evaluator internalizes the welfare loss implied by the type of work offered. This generalization is motivated by the fact that poverty in developing countries is typically correlated with both low wage rates on the private labor market and a high incidence underemployment.

We have offered a simple correction for this deficiency in past assessments of the performance of workfare programs. Our adjustment to measured household consumption allows for the welfare loss from casual manual labor. This is a welfare function consistent with the particular goal of the scheme, as expressed in the legislation creating NREGS. The adjustment involves a single preference parameter that can be readily calibrated to available data.

The proposed adjustment of the welfare measure for the welfare loss from casual manual labor entails a marked difference to standard measures of poverty and inequality. The distributional change implies a lower incidence of poverty, but higher measures of its depth and severity. The adjustment also affects the assessment of the targeting performance of NREGS. Whereas the choice between the unadjusted consumption and our adjusted version does not make a significant difference among the $30 \%$ richest, the assessed targeting performance changes appreciably among the poorest half when we allow for the welfare loss from doing casual manual work. However, allowing for that welfare loss also devalues the benefits to participants. Using survey data for Bihar, we find that this effect dominates the gains from better targeting 
performance implied by allowing for the welfare loss from the type of work done. The scheme reaches even poorer people, but it does less to raise their welfare.

The empirical results imply that if the evaluator ignores the welfare loss from the type of work offered then the earnings gains from NREGS have almost the same impact on poverty as a welfare scheme that transfers the same gross outlay on wages as a uniform lump-sum transfer-a basic income scheme in which everyone receives the same amount whether poor or not. This implies that as long as the NREGS generates non-negligible indirect benefits to participating workers through the assets created or the empowerment benefits it will dominate the welfare scheme. However, the extra benefits from workfare would need to be larger if the evaluator internalizes the welfare losses generated by the type of work offered. Without these extra, indirect, benefits, welfare clearly dominates workfare when everyone involved, including the evaluator, agrees that the work is unpleasant. 


\section{Appendix}

Proposition 1: On the top of voluntary participation and poverty alleviation constraints, the government faces the incentive constraints:

$$
\begin{aligned}
& v\left(B, P W, \alpha_{j}\right) \geq v\left(0,0, \alpha_{j}\right), \forall \alpha_{j}<\alpha_{z} \\
& v\left(B, P W, \alpha_{j}\right) \leq v\left(0,0, \alpha_{j}\right), \forall \alpha_{j}>\alpha_{z}
\end{aligned}
$$

Notice that the second inequality boils down to any non-poor being weakly worse off when participating in the program than in the status quo. This is weaker than the upward adjacent monotonicity incentive compatibility required in BC (1995), but sufficient here since the government chooses between a welfare program and a workfare with a single contract. A costminimizing workfare program is defined by:

$$
\begin{aligned}
\left(B^{*}, P W^{*}\right) & =\left\{z-y\left(P W^{*}, \underline{\alpha}\right)+f\left(P W^{*}+l^{1}\left(B, P W^{*}, \underline{\alpha}\right)\right), P W^{*}\right\} \\
& =\left\{z-\underline{\alpha}\left(l^{0}(\underline{\alpha})-P W^{*}\right)+f\left(l^{0}\left(\alpha_{L}\right)\right), P W^{*}\right\} \\
& =\left\{z-\underline{\alpha} l^{0}(\underline{\alpha})+\underline{\alpha} P W^{*}+f\left(l^{0}(\underline{\alpha})\right), P W^{*}\right\}
\end{aligned}
$$

Notice we have used the assumption that $P W^{*}+l^{1}\left(B^{*}, P W^{*}, \alpha_{i}\right)=l^{0}\left(\alpha_{i}\right) . P W^{*}$ is the work requirement implying high ability workers' indifference between $(B, P W)=\{0,0\}$ and $\left(B^{*}, P W^{*}\right)$, i.e. $P W^{*}$ is such that:

$$
\begin{gathered}
B^{*}+y\left(P W^{*}, \alpha_{z}\right)-h\left(l^{1}\left(B^{*}, P W^{*}, \alpha_{z}\right)+P W^{*}\right)=y\left(0, \alpha_{z}\right)-h\left(l^{0}\left(\alpha_{z}\right)\right) \\
\Uparrow \\
B^{*}+\alpha_{z}\left(l^{0}\left(\alpha_{z}\right)-P W^{*}\right)-h\left(l^{0}\left(\alpha_{z}\right)\right)=\alpha_{z} l^{0}\left(\alpha_{z}\right)-h\left(l^{0}\left(\alpha_{z}\right)\right) \\
\Uparrow \\
B^{*}=\alpha_{z} P W^{*}
\end{gathered}
$$


The cost of this workfare program is $F_{\alpha}\left(\alpha_{z}\right) B^{*}=F_{\alpha}\left(\alpha_{z}\right) \alpha_{z} P W^{*}$. Again we have $P W^{*}+$ $l^{1}\left(B^{*}, P W^{*}, \alpha_{z}\right)=l^{0}\left(\alpha_{z}\right)$. Also notice that $\left(B^{*}, P W^{*}\right)$, can be rewritten in the closed form solution:

$$
\left\{\begin{array}{l}
P W^{*}=\frac{1}{\alpha_{z}-\underline{\alpha}}\left[z-\underline{\alpha} l^{0}(\underline{\alpha})+f\left(l^{0}(\underline{\alpha})\right)\right] \\
B^{*}=\frac{\alpha_{z}}{\alpha_{z}-\underline{\alpha}}\left[z-\underline{\alpha} l^{0}(\underline{\alpha})+f\left(l^{0}(\underline{\alpha})\right)\right]
\end{array}\right.
$$

We see that the higher the gap in wages between the poor and the rich, the lower the work requirement. If the government cares about the welfare loss implied by the work requirement then it has to increase $P W^{*}$. This program generates per capita costs of $B^{*} \times F_{\alpha}\left(\alpha_{z}\right)$.

Now consider a welfare program, $P W=0$, characterized by

$$
B=\mathrm{z}-y(0, \underline{\alpha})+f\left(l^{0}(\underline{\alpha})\right)
$$

(as implied by the poverty alleviation constraint). This leads to the per capita costs:

$$
\begin{gathered}
F_{\alpha}\left(\alpha_{z}\right)\left[z-y(0, \underline{\alpha})+f\left(l^{0}(\underline{\alpha})\right)\right]+\left(1-F_{\alpha}\left(\alpha_{z}\right)\right)\left[z-y(0, \underline{\alpha})+f\left(l^{0}(\underline{\alpha})\right)\right] \\
=z-y(0, \underline{\alpha})+f\left(l^{0}(\underline{\alpha})\right) \\
=z-\underline{\alpha} l^{0}(\underline{\alpha})+f\left(l^{0}(\underline{\alpha})\right) \\
=B^{*} \times \frac{\alpha_{z}-\underline{\alpha}}{\alpha_{z}}
\end{gathered}
$$

The sufficient condition for workfare to be the cost-minimizing option is thus:

$\left(\alpha_{z}-\underline{\alpha}\right)>F_{\alpha}\left(\alpha_{z}\right) \alpha_{z}$, as claimed in Proposition 1. Hence we end up with the same solution as in $\mathrm{BC}$, even though the government is now internalizing part of the welfare loss implied by the time spent on the scheme. This makes sense if one recalls the labor market clearing assumption:

$$
P W^{*}+l^{1}\left(B^{*}, P W^{*}, \alpha_{z}\right)=l^{0}\left(\alpha_{z}\right) .
$$


Proposition 2: In the asymmetric information case the solution found in $\mathrm{BC}$ is altered if one relaxes their assumption that the labor market clears. Under a workfare scheme, the government offers a transfer conditional on a public work requirement:

$$
\begin{gathered}
\left(B^{*}, P W^{*}\right)=\left\{z-y\left(P W^{*}, \underline{\alpha}\right)+f\left(P W^{*}+l^{1}\left(B^{*}, P W^{*}, \underline{\alpha}\right)\right), P W^{*}\right\} \\
=\left\{z-\underline{\alpha}\left(l^{0}(\underline{\alpha})-\underline{s \alpha} P W^{*}\right)+f\left((1-\underline{s}) P W^{*}+l^{0}(\underline{\alpha})\right), P W^{*}\right\} \\
\quad\left\{z-\underline{\alpha} l^{0}(\underline{\alpha})+\underline{s \alpha} P W^{*}+f\left((1-\underline{s}) P W^{*}+l^{0}(\underline{\alpha})\right), P W^{*}\right\}
\end{gathered}
$$

$P W^{*}$ is defined exactly as before, indeed $s_{z}=1$ implies:

$$
\begin{gathered}
B^{*}+y\left(P W^{*}, \alpha_{z}\right)-h\left(l^{1}\left(B^{*}, P W^{*}, \alpha_{z}\right)+P W^{*}\right)=y\left(0, \alpha_{z}\right)-h\left(l^{0}\left(\alpha_{z}\right)\right) \\
\Uparrow \\
B^{*}+\alpha_{z}\left(l^{0}\left(\alpha_{z}\right)-P W^{*}\right)-h\left(l^{0}\left(\alpha_{z}\right)\right)=\alpha_{z} l^{0}\left(\alpha_{z}\right)-h\left(l^{0}\left(\alpha_{z}\right)\right) \\
\Uparrow \\
B^{*}=\alpha_{z} P W^{*}
\end{gathered}
$$

But now $B^{*}=z-\underline{\alpha} l^{0}(\underline{\alpha})+\underline{s \alpha} P W^{*}+f\left((1-\underline{s}) P W^{*}+l^{0}(\underline{\alpha})\right)$. We see that the transfer $B^{*}$ needed to meet the poverty alleviation constraint is a function of the rationing parameter $\underline{s}$. How $B^{*}$ evolves with $\underline{s}$ depends on the slope of $f$ in $(1-\underline{s}) P W^{*}+l^{0}(\underline{\alpha})$, indeed:

$$
\begin{aligned}
\left.\frac{\partial B^{*}}{\partial s}\right|_{s=\underline{s}}>0 & \Leftrightarrow \underline{\alpha} P W^{*}-P W^{*} f^{\prime}\left((1-\underline{s}) P W^{*}+l^{0}(\underline{\alpha})\right)>0 \\
& \Leftrightarrow \underline{\alpha}>f^{\prime}\left((1-\underline{\alpha}) P W^{*}+l^{0}(\underline{\alpha})\right)
\end{aligned}
$$

Next consider welfare. The transfers needed to meet the poverty alleviation constraints are the same as before, namely $z-y(0, \underline{\alpha})+f\left(l^{0}(\underline{\alpha})\right)$. But if one wants to express the per capita costs of such a welfare program as a function of $P W^{*}$ in this set up one gets:

$z-y(0, \underline{\alpha})+f\left(l^{0}(\underline{\alpha})\right)=z-\underline{\alpha} l^{0}(\underline{\alpha})+f\left(l^{0}(\underline{\alpha})\right)$ 


$$
\begin{aligned}
=z-\underline{\alpha} l^{0}(\underline{\alpha}) & +\underline{s \alpha} P W^{*}+f\left((1-\underline{s}) P W^{*}+l^{0}(\underline{\alpha})\right)+f\left(l^{0}(\underline{\alpha})\right)-\underline{s \alpha} P W^{*} \\
& -f\left((1-\underline{s}) P W^{*}+l^{0}(\underline{\alpha})\right)=B^{*}-\underline{s \alpha} P W^{*}-f\left((1-\underline{s}) P W^{*}+l^{0}(\underline{\alpha})\right) \\
= & \alpha_{z} P W^{*}-\underline{s \alpha} P W^{*}+f\left(l^{0}(\underline{\alpha})\right)-f\left((1-\underline{s}) P W^{*}+l^{0}(\underline{\alpha})\right) \\
= & \left(\alpha_{z}-\underline{s \alpha}\right) P W^{*}+f\left(l^{0}(\underline{\alpha})\right)-f\left((1-\underline{s}) P W^{*}+l^{0}(\underline{\alpha})\right)
\end{aligned}
$$

We verify that for $\underline{s}=1$ we have $f\left(l^{0}(\underline{\alpha})\right)=f\left((1-\underline{s}) P W^{*}+l^{0}(\underline{\alpha})\right)$ and we are back to the case described already.

We see that if the government does not internalize the welfare loss then $f\left(l^{0}(\underline{\alpha})\right)=$ $f\left((1-\underline{s}) P W^{*}+l^{0}(\underline{\alpha})\right)=0$ and a workfare is cost minimizing if and only if $\left(\alpha_{z}-\underline{s \alpha}\right)>$ $F_{\alpha}\left(\alpha_{z}\right) \alpha_{z}$, which is less restrictive than $\left(\alpha_{z}-\underline{\alpha}\right)>F_{\alpha}\left(\alpha_{z}\right) \alpha_{z}$ because $\underline{s} \leq 1$. This leads to Proposition 2 with closed form solutions:

$$
\left\{\begin{aligned}
P W^{*} & =\frac{1}{\alpha_{z}-\underline{s \alpha}}\left[z-\underline{\alpha} l^{0}(\underline{\alpha})\right] \\
B^{*} & =\frac{\alpha_{z}}{\alpha_{z}-\underline{s \alpha}}\left[z-\underline{\alpha} l^{0}(\underline{\alpha})\right]
\end{aligned}\right.
$$

Proposition 3: If the government does internalize the welfare loss then:

$$
f\left(l^{0}(\underline{\alpha})\right)-f\left((1-\underline{s}) P W^{*}+l^{0}(\underline{\alpha})\right)>0
$$

Workfare is cost minimizing if and only if:

$$
\left(\alpha_{z}-\underline{s \alpha}\right)+\left(\frac{1}{P W^{*}}\right) f\left(l^{0}(\underline{\alpha})\right)-f\left((1-\underline{s}) P W^{*}+l^{0}(\underline{\alpha})\right)>F_{\alpha}\left(\alpha_{z}\right) \alpha_{z}
$$

From the previous derivation we can rewrite:

$$
P W^{*}=\frac{1}{\alpha_{z}-\underline{s \alpha}}\left[z-\underline{\alpha} l^{0}(\underline{\alpha})+f\left((1-\underline{s}) P W^{*}+l^{0}(\underline{\alpha})\right)\right]
$$

Notice that the existence of a closed form solution for $\left(B^{*}, P W^{*}\right)$ depends now on the invertibility of $f$ with respect to $P W^{*}$. Hence a workfare is cost minimizing if and only if $\left(\alpha_{z}-\underline{s \alpha}\right) K>F_{\alpha}\left(\alpha_{z}\right) \alpha_{z}$, where: 
$K \equiv 1+\frac{f\left(l^{0}(\underline{\alpha})\right)-f\left((1-\underline{s}) P W^{*}+l^{0}(\underline{\alpha})\right)}{z-\underline{\alpha} l^{0}(\underline{\alpha})+f\left((1-\underline{s}) P W^{*}+l^{0}(\underline{\alpha})\right)}=\frac{z-\underline{\alpha} l^{0}(\underline{\alpha})+f\left(l^{0}(\underline{\alpha})\right)}{z-\underline{\alpha} l^{0}(\underline{\alpha})+f\left((1-\underline{s}) P W^{*}+l^{0}(\underline{\alpha})\right)}$

Thus we have Proposition 3. Notice that $f\left(l^{0}(\underline{\alpha})\right)<f\left((1-\underline{s}) P W^{*}+l^{0}(\underline{\alpha})\right)$ because $f^{\prime}()>$.0 and for $\underline{s}<1$ we have $l^{0}(\underline{\alpha})<(1-\underline{s}) P W^{*}+l^{0}(\underline{\alpha})$; hence $K<1$. Again, for $\underline{s}=1$ we are back to the case described above. 


\section{References}

Atkinson, Anthony B., 1987, “On the Measurement of Poverty,” Econometrica 55: 749-64.

Bardhan, Pranab, 1984, Land, Labor and Rural Poverty: Essays in Development Economics. New York: Columbia University Press.

Basu, Arnab K, 2013, “Impact of Rural Employment Guarantee Schemes on Seasonal Labor Markets: Optimum Compensation and Workers' Welfare," The Journal of Economic Inequality, 11: 1-34.

Besley, Timothy, and Stephen Coate, 1992, "Workfare vs. Welfare: Incentive Arguments for Work Requirements in Poverty Alleviation Programs," American Economic Review 82(1): 249-61. , and 1995, “The Design of Income Maintenance Programmes,”

Review of Economics Studies 62: 187-221.

Bhalla, Surjit, 2011, “Does NREGA Really Work?” Business Standard 27 March.

Blundell Richard, Thomas Macurdy and Costas Meghir, 2007, “Labor Supply Models:

Unobserved Heterogeneity, Nonparticipation and Dynamics," Handbook of Econometrics Volume 6A, Chapter 69, Amsterdam: North Holland.

Browning, Martin, 1992, “Children and Household Economic Behavior," Journal of Economic Literature 30: 1434-1475.

Cleveland, W. S., 1979, "Robust Locally Weighted Regression and Smoothing Scatter Plots," Journal of the American Statistical Association 74: 829-836.

Datt, Gaurav and Martin Ravallion, 1992, "Growth and Redistribution Components of Changes in Poverty: A Decomposition with Application to Brazil and India," Journal of Development Economics 38: 275-295. and 1994, "Transfer Benefits from Public Works Employment,"

Economic Journal 104: 1346-1369. and , 1998, "Farm Productivity and Rural Poverty in India,"

Journal of Development Studies 34(4): 62-85.

Deaton, Angus, 1989, "Rice Prices and Income Distribution in Thailand: A Non-Parametric Analysis," Economic Journal 99(395): 1-37. 
Deaton, Angus and Jean Drèze, 2002, "Poverty and Inequality in India: A re-Examination," Economic and Political Weekly September 7: 3729-48.

Drèze, Jean and Reetika Khera (2011), "Employment Guarantee and the Right to Work," in Reetika Khera (ed.) The Battle for Employment Guarantee, New Delhi: Oxford University Press.

Dutta, Puja, Rinku Murgai, Martin Ravallion and Dominique van de Walle, 2012, “Does India's Employment Guarantee Scheme Guarantee Employment?” Economic and Political Weekly 48 (April 21): 55-64. and 2014, Right to Work?

Assessing India's Employment Guarantee Scheme in Bihar. World Bank Report.

Foster, James., J. Greer, and Erik Thorbecke, 1984, “A Class of Decomposable Poverty Measures," Econometrica 52: 761-765.

Gaiha, Raghav, 1997, "Rural Public Works and the Poor: The Case of the Employment Guarantee Scheme in India," in S. Polachek (ed.) Research in Labour Economics, Connecticut: JAI Press.

Imbert, Clement and John Papp, 2011, “Estimating Leakages in India's Employment Guarantee," in Reetika Khera (ed.) The Battle for Employment Guarantee, New Delhi: Oxford University Press.

Jha, Raghbendra, Sambit Bhattacharyya, Raghav Gaiha and Shylashri Shankar, 2009, "'Capture' of Anti-Poverty Programs: An Analysis of the National Rural Employment Guarantee Program in India," Journal of Asian Economics 20(4): 456-464.

Jha, Raghbendra, Raghav Gaiha, Manoj K. Pandey, 2012, “Net Transfer Benefits under India’s Rural Employment Guarantee Scheme,” Journal of Policy Modeling 34(2): 296-311.

Kanbur, Ravi, Michael Keen, Matti Tuomala, 1994a, “Optimal Nonlinear Income Taxation for the Alleviation of Income Poverty,” European Economic Review 38(8): 1613-1632. , 1994b, "Labor Supply and Targeting in Poverty Alleviation Programs," World Bank Economic Review 8(2): 191-211.

Lokshin, Michael, 2006, “Difference-Based Semiparametric Estimation of Partial Linear Regression Models," STATA Journal 6: 377-384.

Mirrlees, James, 1971, “An Exploration in the Theory of Optimum Income Taxation.” Review of Economic Studies 38:175-208. 
Moffitt, Robert, 2006, "Welfare Work Requirements with Paternalistic Government Preferences," Economic Journal 116(515): 441-458.

Pitt, Mark, and Shahidur Khandker, 1998, "The Impact of Group-Based Credit Programs on Poor Households in Bangladesh: Does the Gender of Participants Matter?” Journal of Political Economy 106: 958-96.

Pollak, Robert, and Terence Wales, 1979, "Welfare Comparison and Equivalence Scale," American Economic Review 69: 216-221.

Ravallion, Martin, 2009, "How Relevant is Targeting to the Success of the Antipoverty Program?" World Bank Research Observer 24(3): 205-231. , 2012, "Poverty Lines across the World," Chapter 3 of the Oxford Handbook of the Economics of Poverty, edited by Philip N. Jefferson, Oxford University Press. , 2015, The Economics of Poverty, Oxford and New York: Oxford University Press.

Ravallion, Martin and Gaurav Datt, 1995, "Is Targeting through a Work Requirement Efficient? "Some Evidence for Rural India," in D. van de Walle and K. Nead (eds) Public Spending and the Poor: Theory and Evidence, Baltimore: Johns Hopkins University Press.

Ravallion, Martin, Gaurav Datt, and Shubham Chaudhuri, 1993, "Does Maharashtra's 'Employment Guarantee Scheme' Guarantee Employment? Effects of the 1988 Wage Increase," Economic Development and Cultural Change 41: 251-75.

van de Walle, Dominique, 1985, "Population Growth and Poverty: Another Look at the India Time Series Data," Journal of Development Studies 21(3): 429-39.

World Bank, 2012, World Development Report: Jobs. World Bank, Washington DC. 
Table 1: Summary statistics for $C_{i}, L_{i}$ and $W_{i}$

\begin{tabular}{lllllll}
\hline & NSS & \multicolumn{5}{c}{ Bihar Survey } \\
& \multicolumn{1}{c}{$C_{i}$} & \multicolumn{1}{c}{$L_{i}$} & \multicolumn{1}{c}{$W_{i}$} & $C_{i}$ & $L_{i}$ & $W_{i}$ \\
\hline mean & 236 & 2.4 & 95 & 171 & 1.1 & 76 \\
s.d. & 205 & 1.5 & 48 & 100 & 0.8 & 38 \\
$\mathrm{~N}$ & 59129 & 13793 & 13793 & 3000 & 1201 & 1194 \\
$\min$ & 9 & 0.1 & 8 & 13 & 0.1 & 1 \\
$y(25)$ & 143 & 1.3 & 67 & 109 & 0.6 & 60 \\
$y(50)$ & 193 & 2.0 & 87 & 149 & 0.9 & 70 \\
$y(75)$ & 267 & 3.2 & 110 & 202 & 1.3 & 100 \\
$\max$ & 14738 & 7.0 & 2000 & 2376 & 7.0 & 890 \\
\hline
\end{tabular}

Note: $W$ is in rupees per day, calculated as the total wages received for casual manual work divided by the total number of days of such work provide by the household; $C$ is in rupees per person per week, calculated as total household consumption per week divided by the number of people in the household; $L$ is in days per capita, calculated as total number of days of casual manual work divided by household size. $y(p)$ denotes the value of each variable at the $p$ 'th percentile. 
Table 2: Distribution across quintiles before and after adjustment $(\%, \omega=70)$

NSS all rural India

\begin{tabular}{|llllllll|}
\hline \multirow{2}{*}{ Quintiles } & & \multicolumn{6}{c}{$C_{i}$} \\
\hline & & 1 & 2 & 3 & 4 & 5 & Total \\
& 2 & 11.6 & 3.1 & 3.0 & 1.7 & 0.7 & 20.0 \\
$C_{i}^{A}$ & 3 & 0.0 & 11.8 & 6.6 & 1.2 & 0.5 & 20.0 \\
& 4 & 0.0 & 0.0 & 7.0 & 12.2 & 0.9 & 20.0 \\
& 5 & 0.0 & 0.0 & 0.0 & 2.7 & 17.3 & 20.0 \\
& Total & 19.9 & 20.0 & 20.0 & 20.0 & 20.1 & 100.0 \\
\hline
\end{tabular}

\section{World Bank Bihar survey}

\begin{tabular}{|llllllll|}
\hline \multirow{2}{*}{ Quintiles } & & \multicolumn{6}{c}{$C_{i}$} \\
\hline & & 1 & 2 & 3 & 4 & 5 & Total \\
& 1 & 11.0 & 4.6 & 2.2 & 1.9 & 0.5 & 20.2 \\
& 2 & 9.1 & 5.5 & 3.4 & 1.6 & 0.3 & 19.9 \\
$C_{i}^{A}$ & 3 & 0.0 & 9.9 & 7.6 & 2.2 & 0.4 & 20.0 \\
& 4 & 0.0 & 0.0 & 6.9 & 11.9 & 1.2 & 20.0 \\
& 5 & 0.0 & 0.0 & 0.0 & 2.4 & 17.6 & 20.0 \\
& Total & 20.0 & 20.0 & 20.0 & 20.0 & 20.0 & 100.0 \\
\hline
\end{tabular}

Table 3: Gini coefficients

\begin{tabular}{|c|c|c|c|c|}
\hline & \multirow{2}{*}{$\begin{array}{l}\text { Using original } \\
\text { consumption }\left(C_{i}\right) \\
\omega=0\end{array}$} & \multicolumn{3}{|c|}{$\begin{array}{l}\text { Using consumption } \\
\text { adjusted for welfare loss from work }\left(C_{i}^{A}=C_{i}-\omega L_{i}\right)\end{array}$} \\
\hline & & $\omega=35$ & $\omega=70$ & $\omega=105$ \\
\hline NSS & 0.31 & 0.39 & 0.56 & 0.78 \\
\hline Bihar Survey & 0.27 & 0.31 & 0.39 & 0.50 \\
\hline
\end{tabular}


Table 4: Poverty measures with and without the adjustment for a welfare loss from casual manual work

\begin{tabular}{lcccc}
\hline & $\begin{array}{c}\text { Unadjusted } \\
\text { consumption } \\
\omega=0\end{array}$ & $\begin{array}{l}\text { Adjusted } \\
\text { consumption } \\
\omega=35\end{array}$ & $\omega=70$ & $\omega=105$ \\
\hline $\begin{array}{l}\text { NSS all rural India } \\
\text { Poverty gap } \\
\text { index }\end{array}$ & 13.7 & 20.9 & 34.8 & 51.1 \\
$\begin{array}{l}\text { Squared poverty } \\
\text { gap index }\end{array}$ & 5.1 & 14.7 & 43.4 & 99.5 \\
\hline $\begin{array}{l}\text { Bihar Survey } \\
\begin{array}{l}\text { Poverty gap } \\
\text { index }\end{array}\end{array}$ & 14.2 & 13.9 & 15.2 & 17.2 \\
$\begin{array}{l}\text { Squared poverty } \\
\text { gap index }\end{array}$ & 5.6 & 5.5 & 6.4 & 8.1 \\
\hline
\end{tabular}

Note: Median $\left(Q_{50}\left(C_{i}^{1}-\omega L_{i}^{1}\right)\right)$ as the poverty line.

Table 5: Impacts of NREGS on poverty in Bihar with and without the adjustment for a welfare loss from casual manual work

\begin{tabular}{|c|c|c|c|c|c|c|}
\hline & & & $\omega=0$ & $\omega=35$ & $\omega=70$ & $\omega=105$ \\
\hline \multirow{9}{*}{ 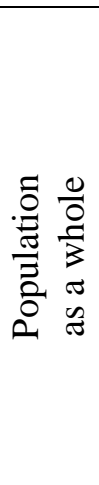 } & \multirow{3}{*}{$\begin{array}{l}\text { Headcount } \\
\text { index }\end{array}$} & $C_{i}^{0}-\omega L_{i}^{0}$ & 50 & 50 & 50 & 50 \\
\hline & & $C_{i}^{1}-\omega L_{i}^{1}$ & 48.5 & 49.2 & 49.6 & 49.6 \\
\hline & & Impact & -1.5 & -0.8 & -0.4 & -0.4 \\
\hline & \multirow{3}{*}{$\begin{array}{l}\text { Poverty } \\
\text { gap index }\end{array}$} & $C_{i}^{0}-\omega L_{i}^{0}$ & 13.8 & 16.5 & 23.6 & 32.1 \\
\hline & & $C_{i}^{1}-\omega L_{i}^{1}$ & 13.2 & 16 & 23.1 & 31.7 \\
\hline & & Impact & -0.6 & -0.5 & -0.5 & -0.4 \\
\hline & \multirow{3}{*}{$\begin{array}{l}\text { Squared } \\
\text { poverty } \\
\text { gap index }\end{array}$} & $C_{i}^{0}-\omega L_{i}^{0}$ & 5.3 & 8 & 17.4 & 35.5 \\
\hline & & $C_{i}^{1}-\omega L_{i}^{1}$ & 5.0 & 7.6 & 16.9 & 35 \\
\hline & & Impact & -0.3 & -0.4 & -0.5 & -0.5 \\
\hline \multirow{9}{*}{ 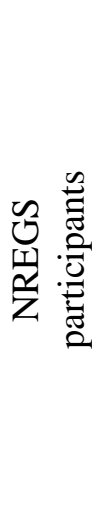 } & \multirow{3}{*}{$\begin{array}{l}\text { Headcount } \\
\text { index }\end{array}$} & $C_{i}^{0}-\omega L_{i}^{0}$ & 60 & 62.4 & 67.3 & 68.1 \\
\hline & & $C_{i}^{1}-\omega L_{i}^{1}$ & 54 & 59.5 & 65.4 & 66.7 \\
\hline & & Impact & -6 & -2.9 & -1.9 & -1.4 \\
\hline & \multirow{3}{*}{$\begin{array}{l}\text { Poverty } \\
\text { gap index }\end{array}$} & $C_{i}^{0}-\omega L_{i}^{0}$ & 18.5 & 23.3 & 33.2 & 44.9 \\
\hline & & $C_{i}^{1}-\omega L_{i}^{1}$ & 16.4 & 21.1 & 31.1 & 43.1 \\
\hline & & Impact & -2.1 & -2.2 & -2.1 & -1.8 \\
\hline & \multirow{3}{*}{$\begin{array}{l}\text { Squared } \\
\text { poverty } \\
\text { gap index }\end{array}$} & $C_{i}^{0}-\omega L_{i}^{0}$ & 7.8 & 11.7 & 23.6 & 45.3 \\
\hline & & $C_{i}^{1}-\omega L_{i}^{1}$ & 6.5 & 10.2 & 21.7 & 43.3 \\
\hline & & Impact & -1.3 & -1.5 & -1.9 & -2.0 \\
\hline
\end{tabular}

Note: The poverty lines are the adjusted medians for (adjusted) pre-NREGS distributions for the population as a whole $\left(Q_{50}\left(C_{i}^{0}-\omega L_{i}^{0}\right)\right)$. 
Table 6: Impact on poverty of a welfare scheme providing an untargeted basic income with the same budget cost

\begin{tabular}{lccccc}
\hline & & $\omega=0$ & $\omega=35$ & $\omega=70$ & $\omega=105$ \\
\hline \multirow{4}{*}{ Headcount index } & $C_{i}^{0}-\omega L_{i}^{0}$ & 50 & 50 & 50 & 50 \\
& $\widetilde{C}_{l}$ & 48.6 & 48.2 & 48.8 & 48.5 \\
& Impact & $\mathbf{- 1 . 4}$ & $\mathbf{- 1 . 8}$ & $\mathbf{- 1 . 2}$ & $\mathbf{- 1 . 5}$ \\
\cline { 2 - 6 } Poverty gap index & $C_{i}^{0}-\omega L_{i}^{0}$ & 13.8 & 16.5 & 23.6 & 32.1 \\
& $\widetilde{C}_{\iota}$ & 12.9 & 15.6 & 22.6 & 31.1 \\
& Impact & $\mathbf{- 0 . 9}$ & $\mathbf{- 0 . 9}$ & $\mathbf{- 1 . 0}$ & $\mathbf{- 1 . 0}$ \\
\cline { 2 - 6 } Squared poverty index & $C_{i}^{0}-\omega L_{i}^{0}$ & 5.3 & 8 & 17.4 & 35.5 \\
& $\widetilde{C}_{l}$ & 4.9 & 7.4 & 16.5 & 34.2 \\
& Impact & $\mathbf{- 0 . 4}$ & $\mathbf{- 0 . 6}$ & $\mathbf{- 0 . 9}$ & $\mathbf{- 1 . 3}$ \\
\hline
\end{tabular}


Figure 1: Wage rates, unemployment and consumption per capita in rural India 2010
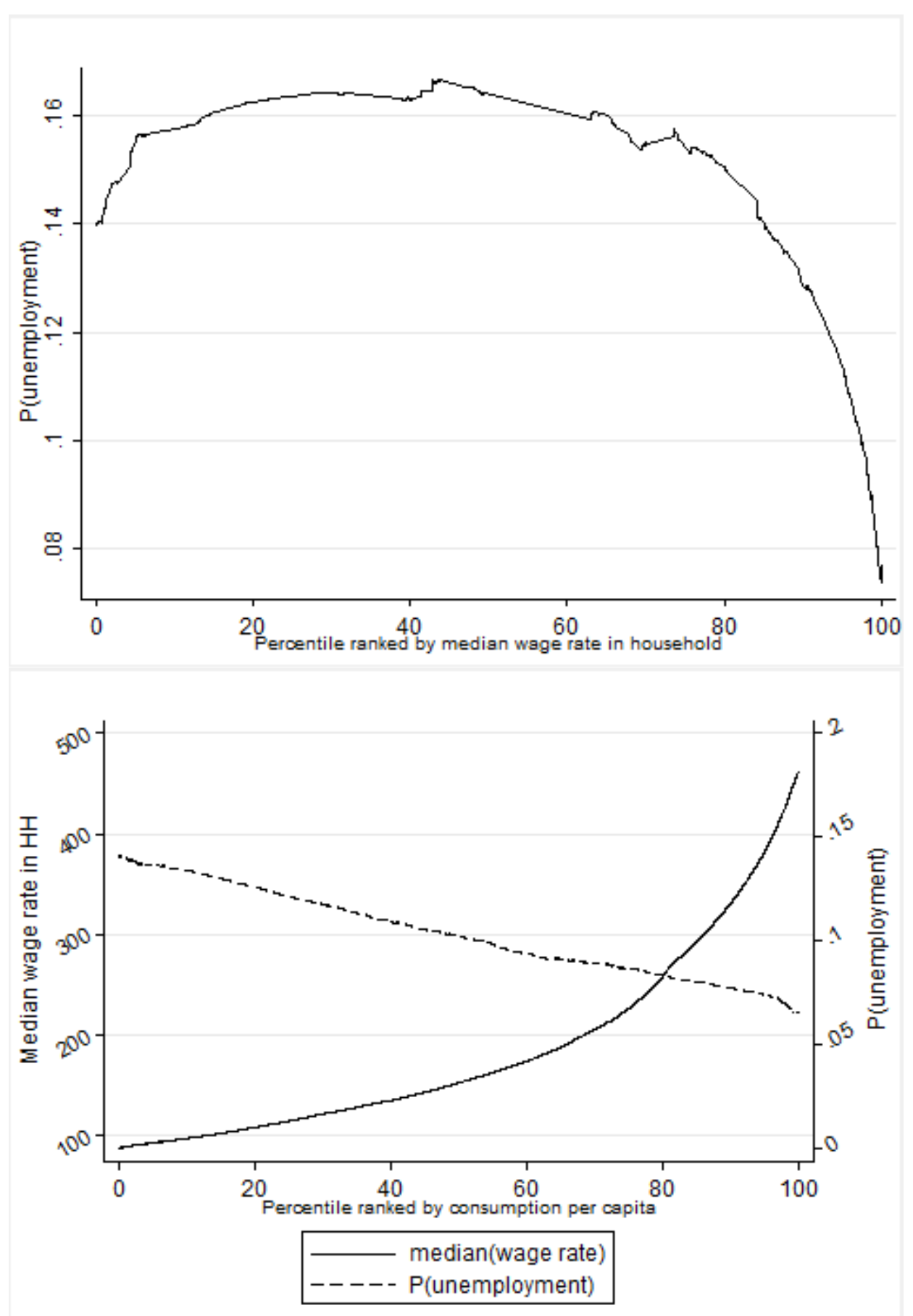

Note: $\mathrm{P}$ (unemployment) is an estimate of $\mathbb{P}\left(\right.$ unemployment $\left.\mid F_{C}(C)\right)$ the conditional probability to have at least one adult household's member reporting at least one half day of unemployment in the week ended in the NSS. Wages in Rupees per day.

Source: Authors' calculations from the National Sample Survey for 2009/10. 
Figure 2: Participation rate in casual manual work as a function of household consumption per capita in NSS

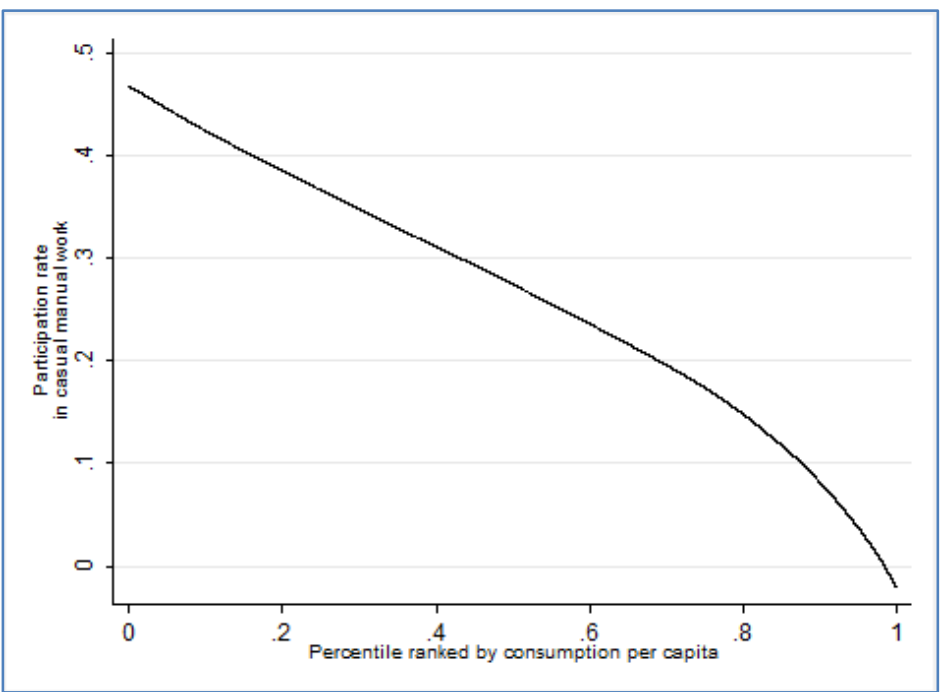

Participation rate in casual manual work as a function of household consumption per capita in World Bank Bihar survey

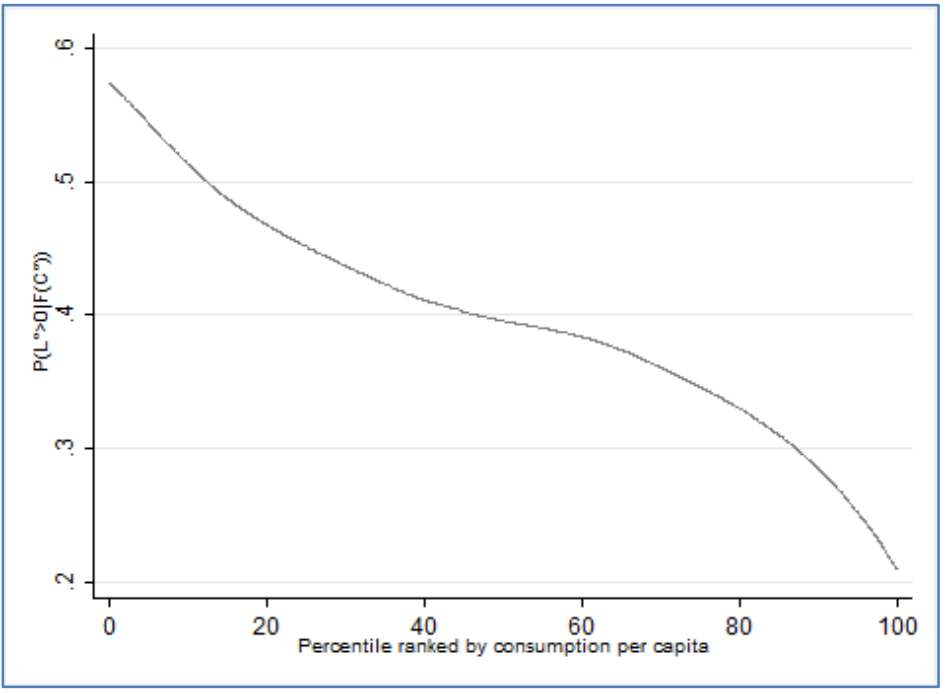

Note: This curve is an estimate of $\mathbb{P}\left(\right.$ some casual manual work $\left.\mid F_{C}(C)\right)$, the conditional probability to have at least on household's member reporting at least one half day of casual manual work in the week ended. The curve's fit based on NSS allows for state fixed effects. The estimate for Bihar's survey is based on measure of casual manual work and consumption in the absence of the scheme. 


\section{Figure 3: Kernel density estimation of $W_{i}^{m}$ distribution}

NSS all rural India

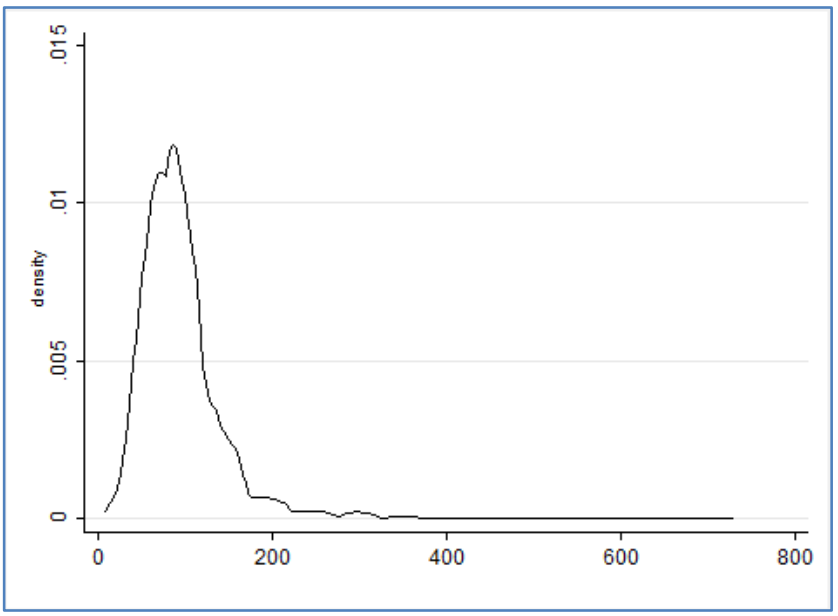

World Bank Bihar survey

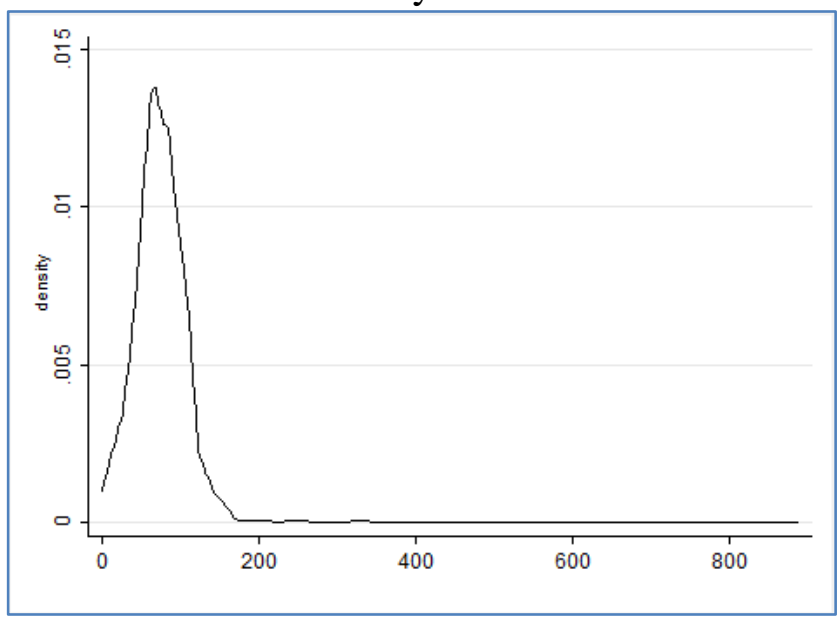

Figure 4: Cumulative Density Functions

NSS all rural India

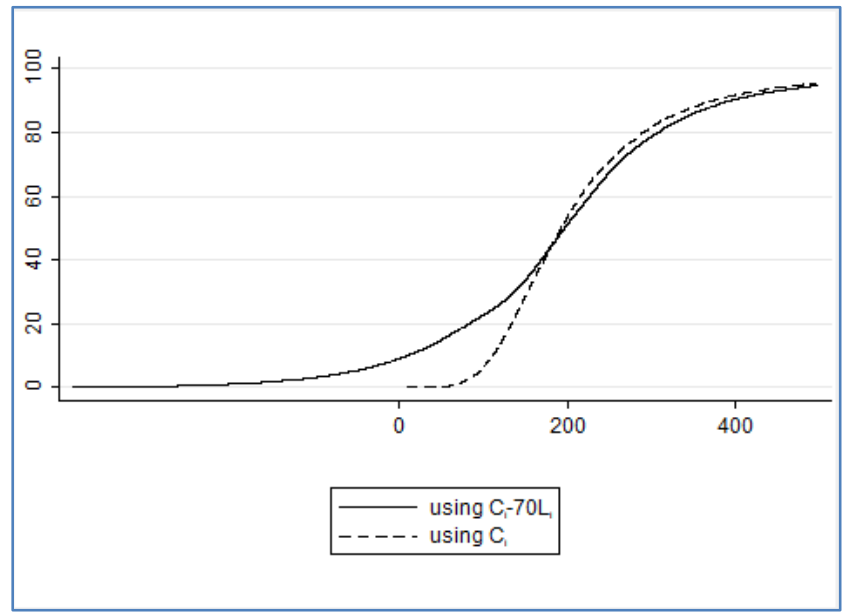

World Bank Bihar survey

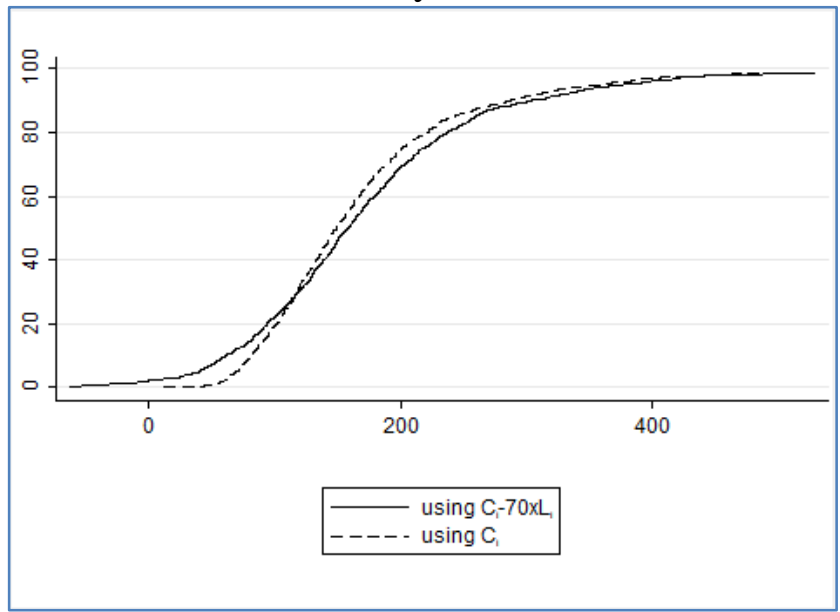

Note: As explained in the main text the two welfare measures used here are not level comparable. For the purpose of this graph we normalize $C_{i}^{A}$ such that it has same mean as $C_{i}$ and we comment in the text on the curvature of these cumulative density functions. 


\section{Figure 5: Lorenz Curves}

NSS all rural India

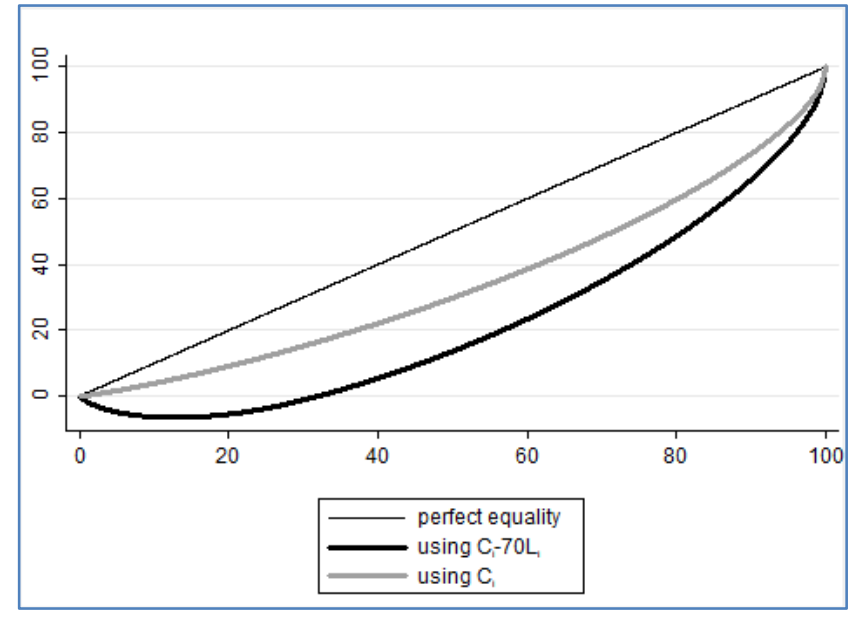

World Bank Bihar survey

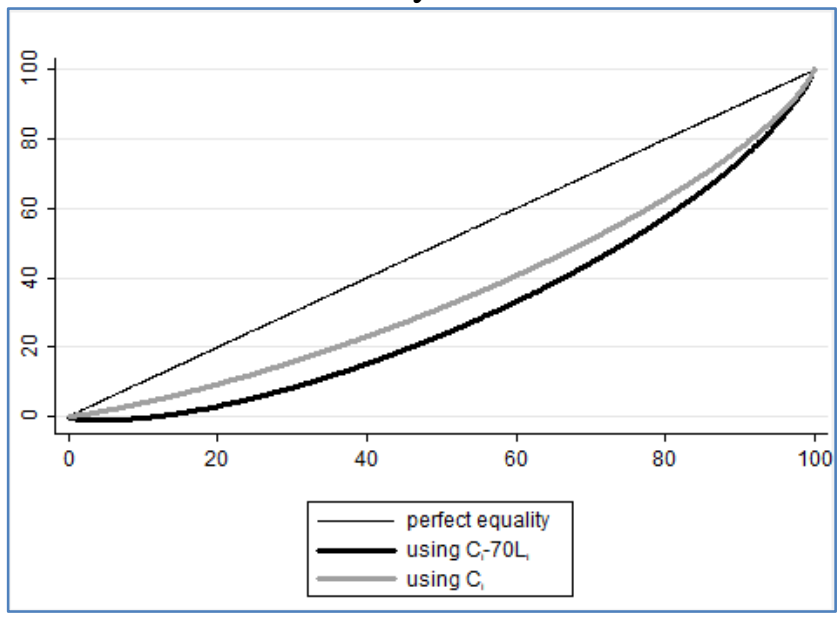




\section{Figure 6: NREGS participation rates}

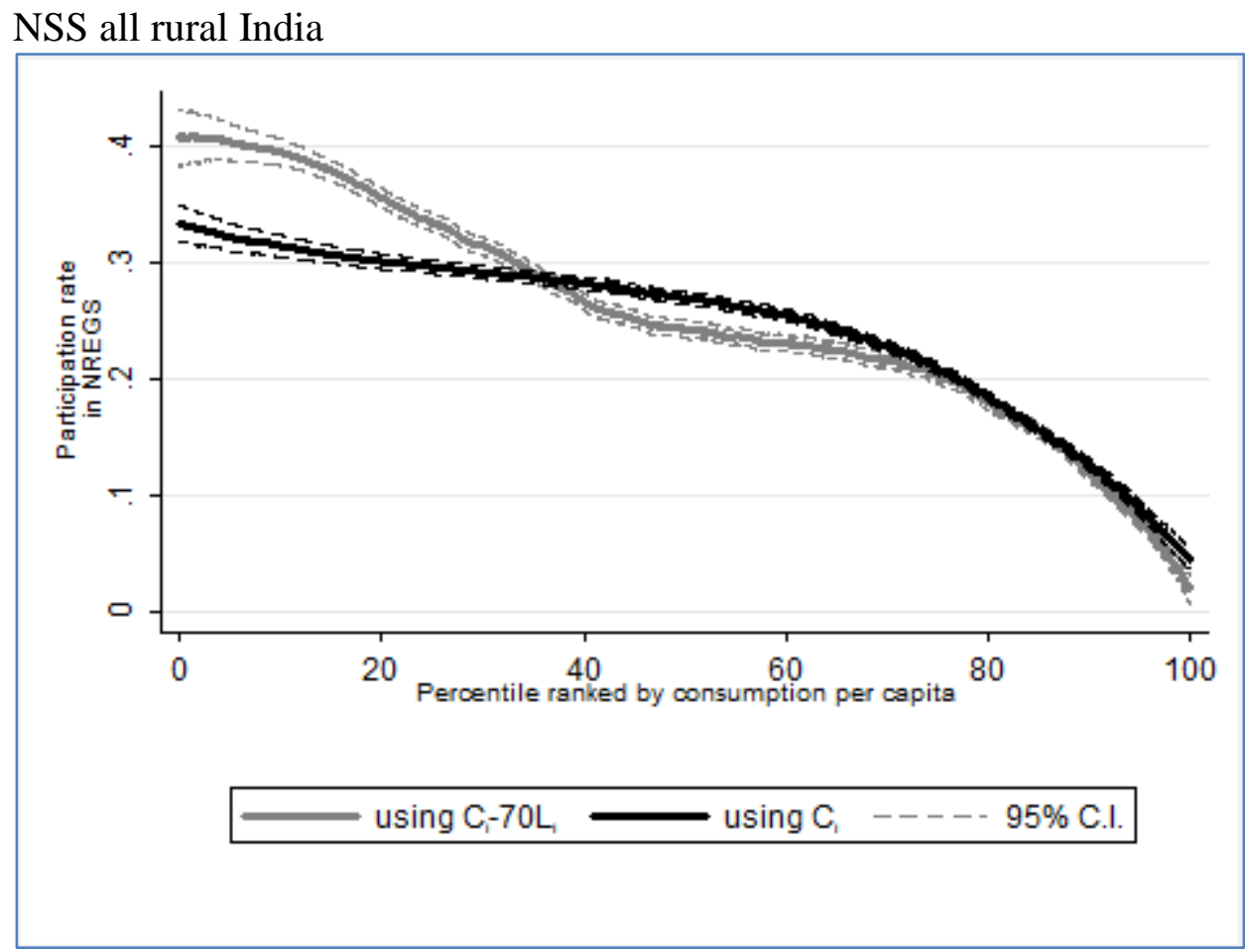

World Bank Bihar survey

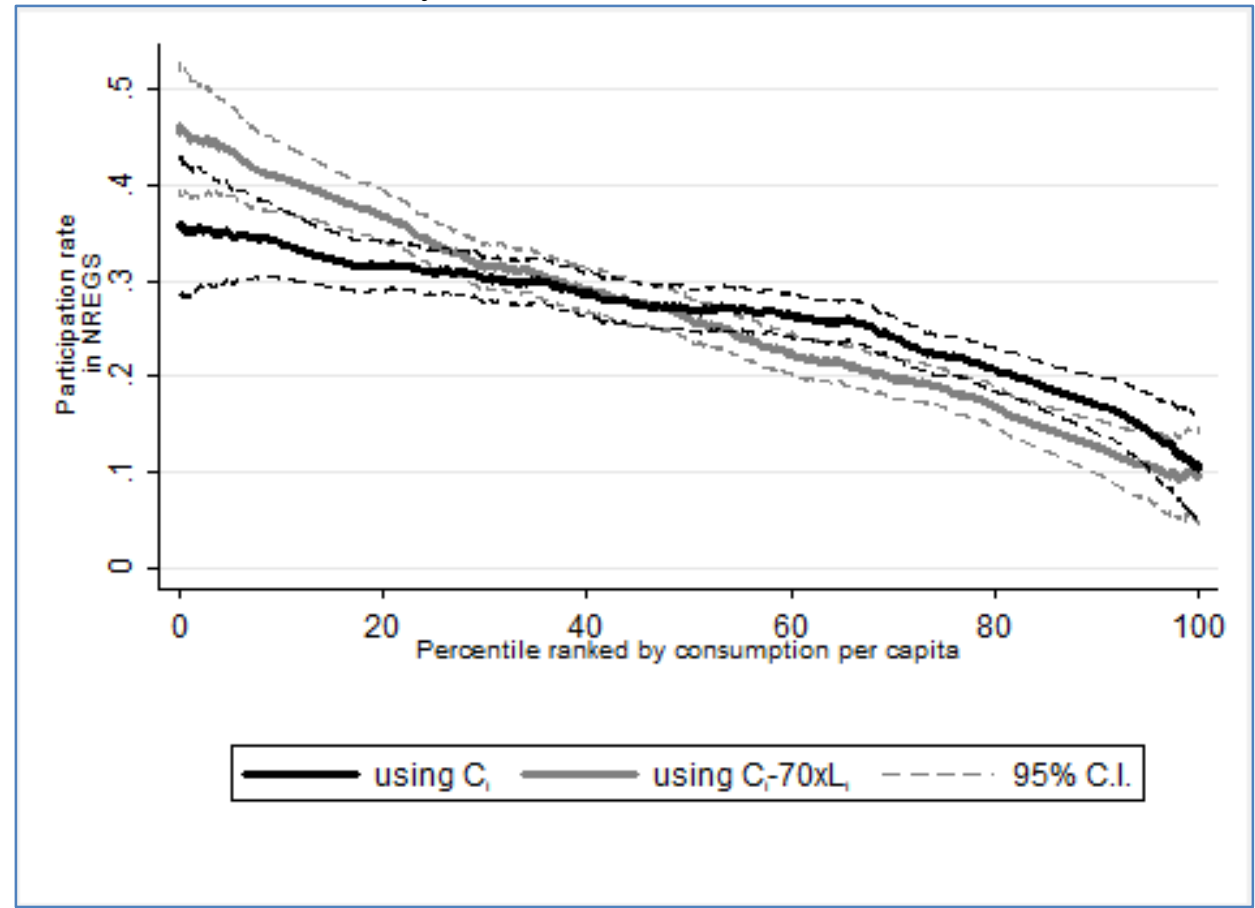

Note: non-parametric regression function, estimates based on cubic splines. 
Figure 7: NREGS participation rates for alternative parameter values

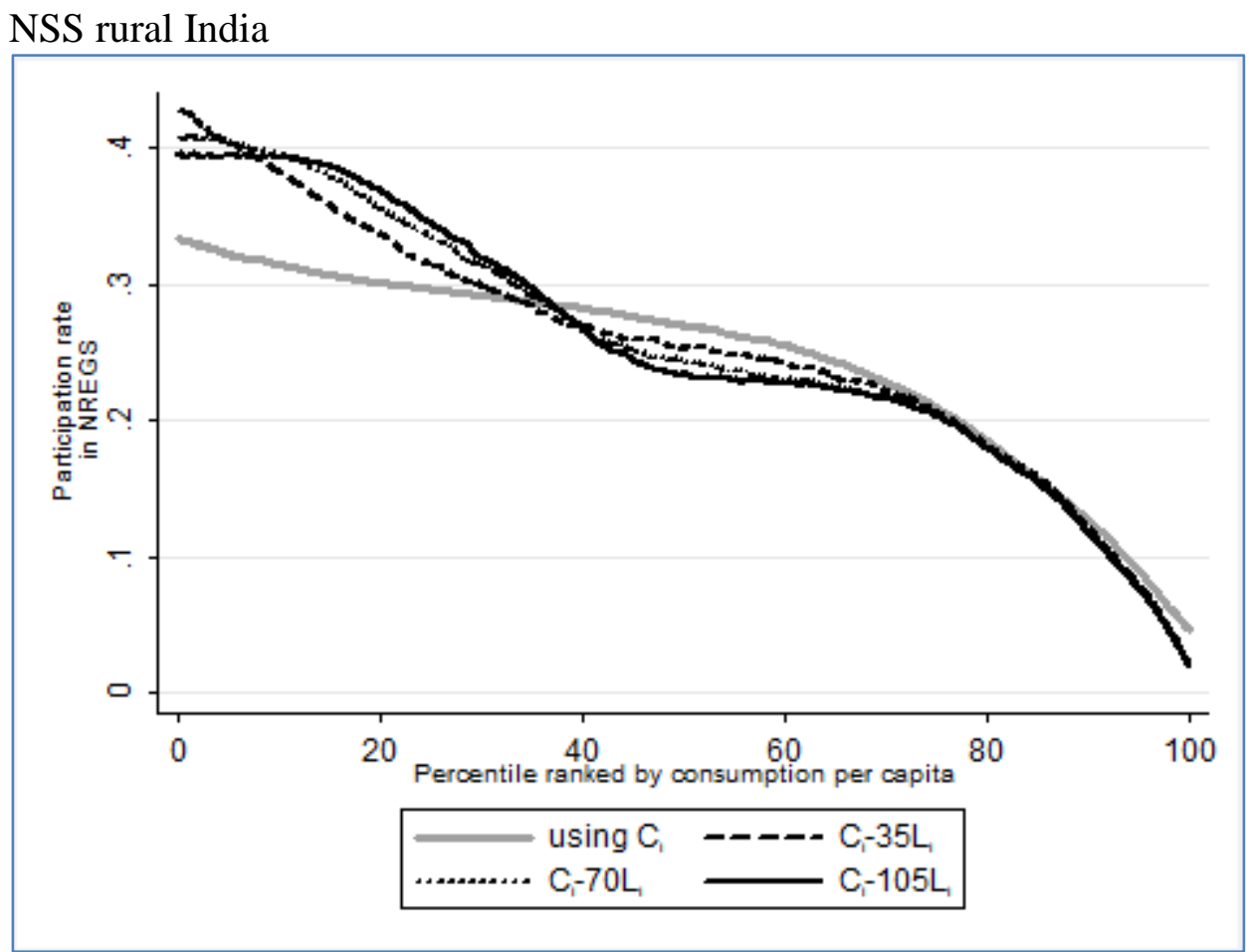

World Bank Bihar survey

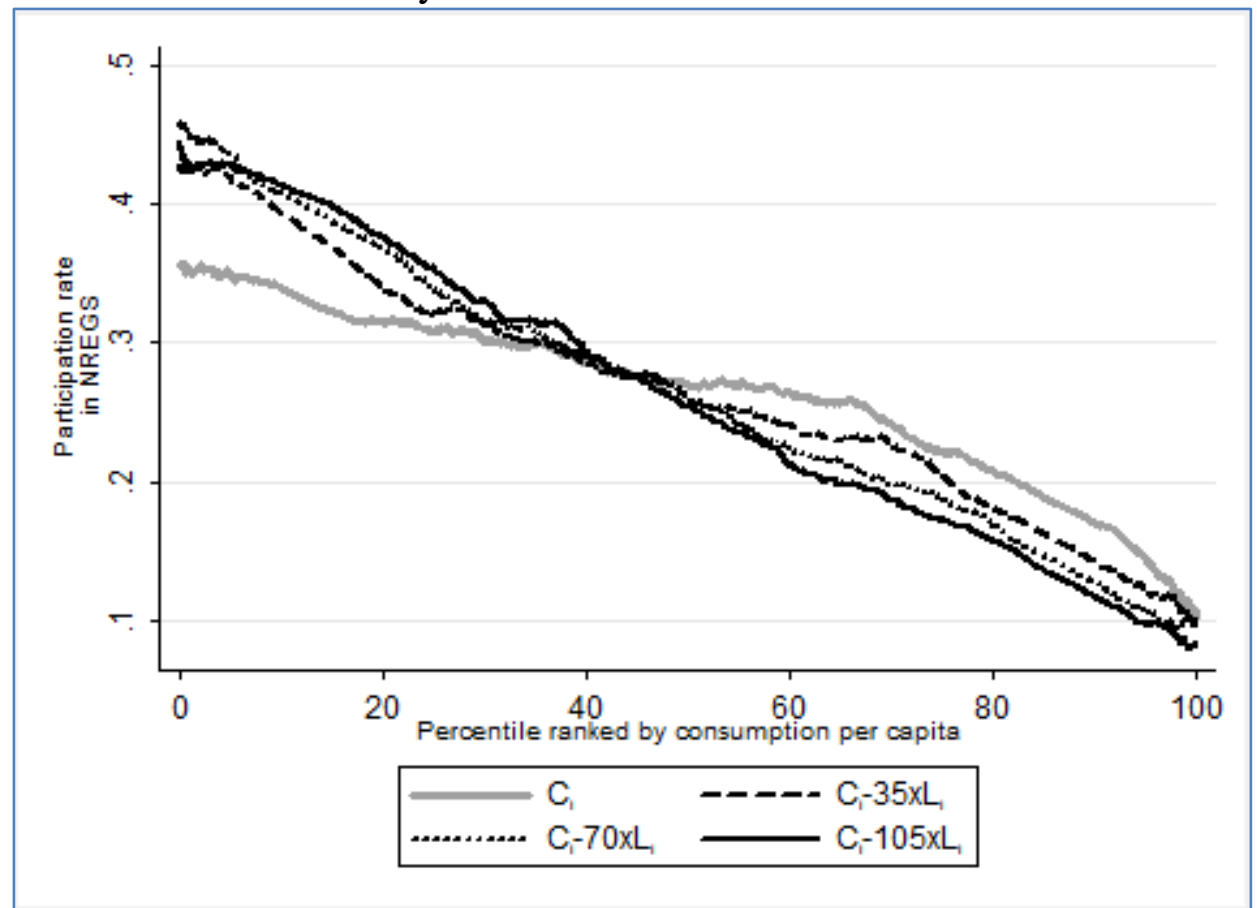

Note: non-parametric regression function, estimates based on cubic splines. 
Figure 8: Net gains from NREGS using World Bank Bihar Survey

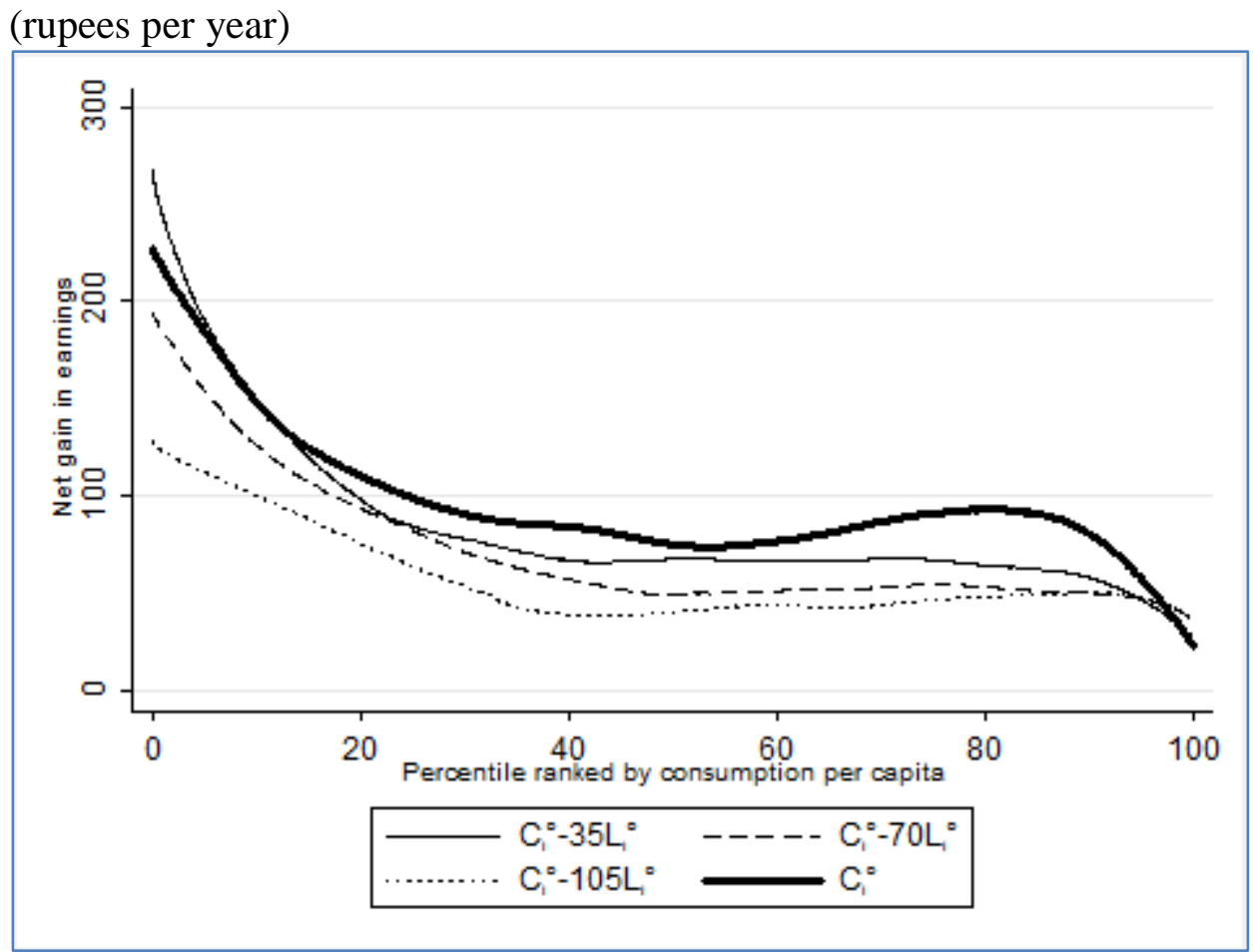

(share of post-NREGS consumption)

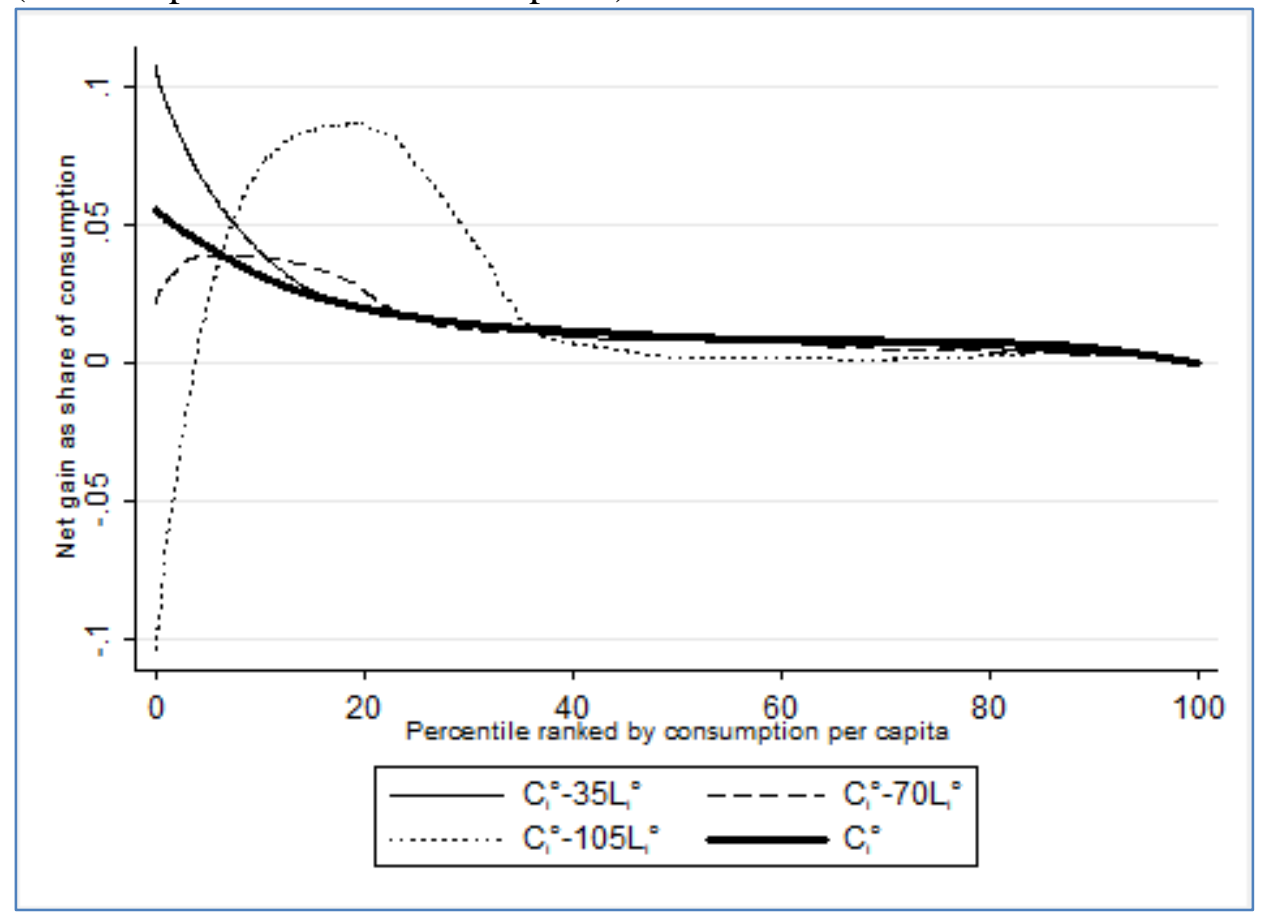

Note: Ranked by pre-NREGS consumption. 